\title{
Colourful Chemistry - from Hybrid Flow Batteries to a Powerful Redox Flow Battery with Impressive Colour Changes for a Phenomenological Approach
}

\author{
Jana Novotny*, Dominik Quarthal, Marco Oetken \\ University of Education Freiburg, Department of Chemistry, Physics, Technology and their teaching methodologies, \\ Kunzenweg 21, 79117 Freiburg im Breisgau, Germany \\ *Corresponding author: jana.novotny@ph-freiburg.de
}

Received January 13, 2019; Revised February 22, 2019; Accepted March 29, 2019

\begin{abstract}
The energy transition towards a larger share of renewables requires energy storage devices with redox flow batteries playing a central role for stationary large-scale storage. The most promising and developed one is the vanadium redox flow battery. However, vanadium compounds are toxic, harmful to the environment and hardly suitable for use in schools - in addition, the worldwide occurrence of vanadium minerals is limited. In Freiburg, the aim of a research project was to make the topic of storage systems accessible to students both at university and in chemistry classes, because they will be the generation that will or must help shape this development. Therefore, hybrid flow batteries with harmless electrolytes, a common metal electrode and a simplified construction needed to be built for school application. Utensils from medical technology such as plastic syringes or extension lines are well suited for building cost-effective hybrid flow batteries for chemistry lessons. With such materials, electrolytes can be circulated with a pump that generates an efficient electrolyte flow. Freiburg's design makes it possible to charge and discharge electrolytes in just a few minutes and the electrochemical reactions get visible through colour changes. In the field of redox flow batteries where the energy is stored in two electrolytes, a high-performance cell based on iron and cerium salts is also presented. With this battery, the anolyte and catholyte can be oxidised or reduced in a short time and electrolytes which change their colours during the electrochemical reaction are used as well. Thus, the operating principle of flow batteries can impressively be demonstrated by changing the properties of the electrolytes at the phenomenological level.
\end{abstract}

Keywords: redox flow battery, hybrid flow battery, iron, cerium, graphite felt, colour changes, electrochemistry

Cite This Article: Jana Novotny, Dominik Quarthal, and Marco Oetken, "Colourful Chemistry - from Hybrid Flow Batteries to a Powerful Redox Flow Battery with Impressive Colour Changes for a Phenomenological Approach." World Journal of Chemical Education, vol. 7, no. 2 (2019): 120-135. doi: $10.12691 /$ wjce-7-2-12.

\section{Introduction}

With the adoption of the Renewable Energy Sources Act in 2016, Germany has set itself the target of increasing the share of electricity generated from renewable energy sources to $40-45 \%$ by 2025 and to at least $80 \%$ by 2050 [1]. In Germany, renewables are mainly generated from solar and wind energy. These energy sources are fluctuating because of changes in the climate and therefore, on sunny and windy days more energy can be produced than consumed. According to studies by the National Research Council (CNRC-NRC), this can have a negative impact on the electric grid by destabilising it [2]. On the other hand, the energy demand cannot be met on cloudy and windless days (= so-called dark doldrums). To address the challenge of dark doldrums, energy storage systems will play an increasingly important role.
Unlike mobile energy storage systems, stationary storage systems do not have to focus on high energy and power density or on a compact design. Much more important for use as stationary network storage are reliability and durability coupled with low costs for storage times of several hours [3]. The most common battery to date is the lead-acid battery, which has low investment costs but, compared to other storage systems, only a small number of charging and discharging cycles can be achieved and the battery needs to be replaced. Therefore, lead-acid batteries do not have the potential for stationary long-term storage. Other battery systems such as nickel-cadmium, nickel-metal hydride or lithium-ion batteries have significantly higher energy densities and cycle numbers. However, they require considerably higher investment costs and therefore do not represent a workable alternative for a large-scale energy storage. The most suitable system for stationary large-scale storage with high cycle rates and low investment costs is the redox flow battery: Such cells offer independent scalability of energy 
and power, a modular design with the possibility of replacing defective components and cost-effective energy storage materials. Therefore, they can be an essential key to the success of the energy transition (not only) in Germany [4].

As in most batteries, reversible reactions take place at the electrodes in redox flow batteries. The special characteristic of these batteries is that the electroactive substances are fluids (liquids, suspensions, etc.). This makes it possible to guarantee the decoupling of energy and power [4]. The electrolytes flow across the electrodes converting chemical energy directly into electricity through reversible oxidation/reduction. The working fluids are then transferred via pumps to separate storage tanks in their charged or discharged state. The size of the tanks determines the energy density (or: specific energy) and the power of the battery is limited by the performance, size and number of stacks. The low specific energy compared to other batteries (all vanadium redox flow battery $25-35 \mathrm{Wh} / \mathrm{kg}$ [5], lithium-ion battery $120-150 \mathrm{Wh} / \mathrm{kg}$ [6]) can be modified by optimising the tank size and the concentration of the electroactive material.

\subsection{Components of a Redox Flow Battery}

A redox flow battery consists of at least one electrochemical cell and two separate tanks. Figure 1 shows a possible technical design of an electrochemical cell in a redox flow battery: The two half-cells are spatially separated by a membrane (a). Flow frames (b) are designed for a uniform electrolyte flow in the cell. A graphite felt (c), which represents the electrode material of the cell, is placed inside each flow frame. To prevent the electrolyte from leaking out of the cell, two graphite bipolar plates (d) are combined with the electrodes. Finally, an insulating plate (e) prevents electrical contact between the end plates from the stack. The end plate with current collector (f) physically separates and electrically connects adjacent cells [4].

Alternatively, a fuel cell-like design can be realised for redox flow batteries (Figure 2) [4]. Instead of a flow frame and a graphite felt, a flow channel consisting of structured graphite plates and porous diffusion electrodes is used. In this way, the path-lengths for the diffusion of ions should be kept as short as possible so that each ion can be oxidised or reduced. Compared to the first design, the disadvantage of this one is that it is more difficult to arrange several cells into stacks.

In summary, a redox flow battery comprises the following main units: several cells which are electrically connected in series into stacks, pumps, fluid technology, heat management and at least a pair of storage tanks [4].

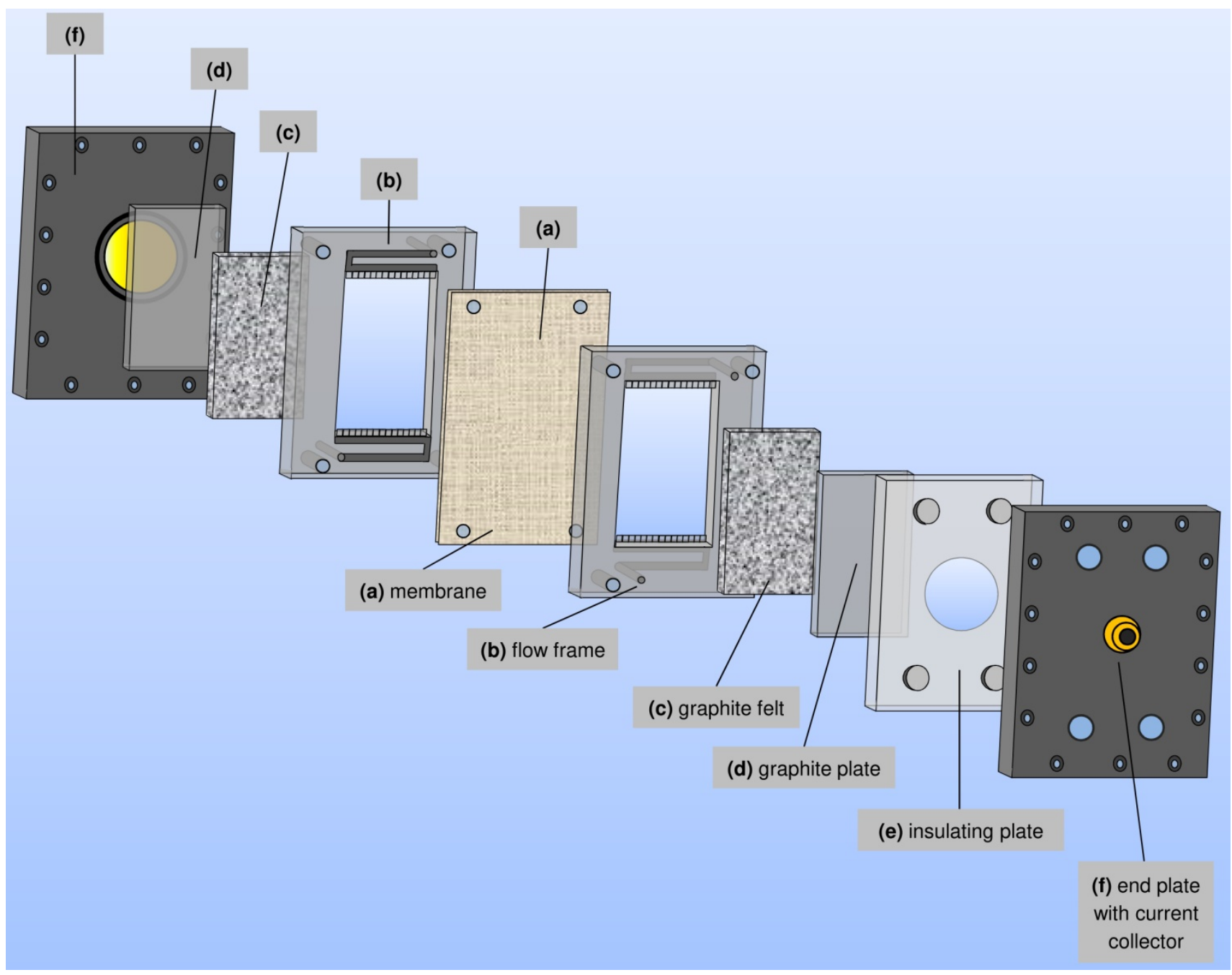




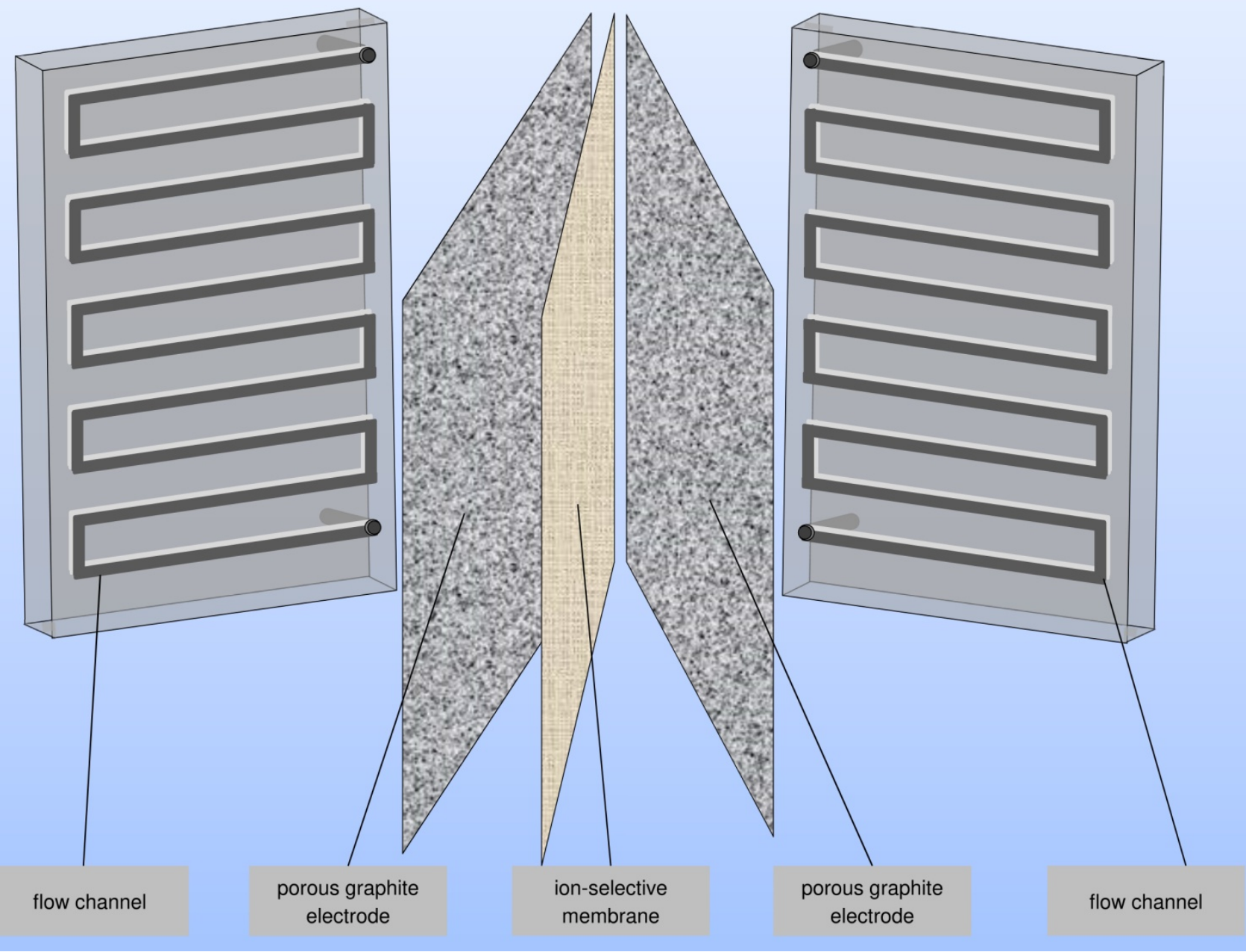

Figure 2. Fuel cell-like design of a redox flow battery

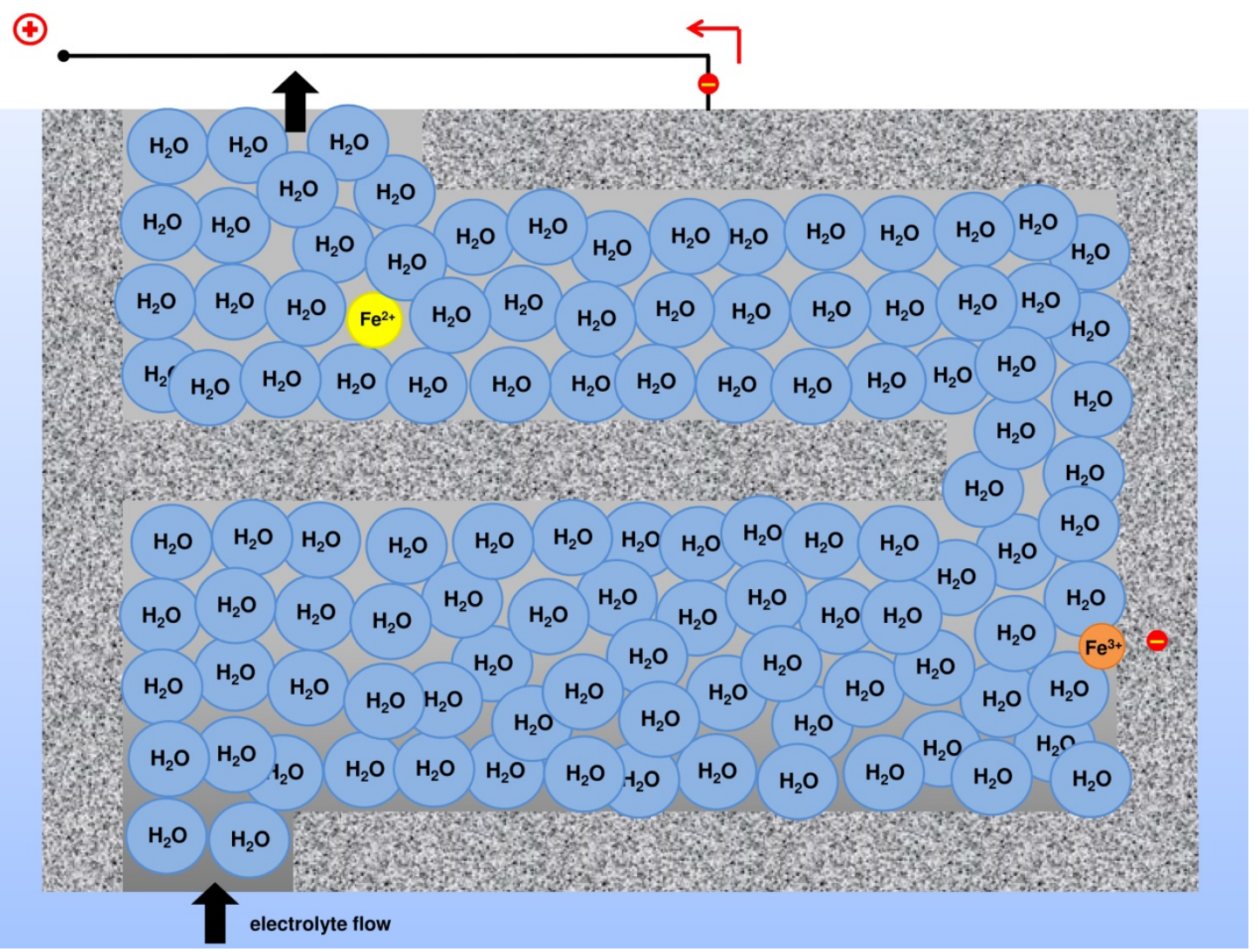

Figure 3. Significance of a high surface area of the electrode material due to the ratio of iron ions to water molecules in a $1 \mathrm{M}$ solution 


\subsection{Electrode Materials in Redox Flow Batteries}

As already mentioned above, energy storage systems must be cost-effective on a large scale - and that is why water-based electrolytes are often used. However, the voltage of the battery is then limited to the decomposition voltage for the electrolysis of water (1.23 V, [7]). Therefore, electrode materials must be chosen with a wide potential operation range. For this reason - despite their low electrical conductivity and lower mechanical stability compared to metal electrodes - carbon-based electrodes find application in redox flow batteries [8].

Since the electrodes are decisive for the performance of the redox flow battery, graphite electrodes with a high specific surface area must be used. This is also important to oxidise/reduce all electroactive species. This will be illustrated using a $\mathrm{Fe}^{2+}$-solution as an example (Figure 3): The concentration of water is $55.5 \mathrm{~mol} / \mathrm{L}$, the particle ratio in an aqueous $\mathrm{Fe}^{2+}$-solution (with the concentration $\mathrm{c}=1 \mathrm{~mol} / \mathrm{L}$ ) is thus approx. 55 to 1 . To increase the probability that all $\mathrm{Fe}^{2+}$-ions diffuse to the electrode $(+$ pole) during a charging process and get oxidised to $\mathrm{Fe}^{3+}$, the surface area of the electrode must be as large as possible in relation to the electrolyte volume. For this reason, a graphite felt with a high specific surface area or a fuel cell-like design as described above is used.

\subsection{Operating Principle of Redox Flow Batteries}

The most developed redox flow battery is the already mentioned vanadium redox flow battery. This system exploits the ability of vanadium to exist in four different oxidation states $\left(\mathbf{V}^{2+}, \mathbf{V}^{3+}, \mathbf{V}^{4+}\right.$ and $\left.\mathbf{V}^{5+}\right)$. The advantage is that with a possible cross-over, where e.g. a $V^{5+}$-ion diffuses through the membrane into the anolyte, it can be reduced again to $\mathbf{V}^{2+}$ at the anode. The crosscontamination is thus mitigated, and the self-discharge of the battery is negligible [4].

Since the electroactive substances are dissolved in the electrolyte and the energy is therefore no longer stored in the electrodes but in two different liquids, the electrolyte that is oxidised during the discharge cycle is called anolyte and the one that is reduced during the discharge cycle is called catholyte.

Before charging, $\mathbf{V}^{3+}$ is dissolved in the anolyte and $\mathrm{V}^{4+}$ in the catholyte. During charging operation (Figure 4, left), the electrolytes are pumped into the electrochemical cell across the electrodes. The $\mathrm{V}^{4+}$-ion is oxidised to $\mathrm{V}^{5+}$, the released electron is transferred to the anode, where the $\mathrm{V}^{3+}$-ion of the anolyte is converted to a $\mathbf{V}^{2+}$-ion. To maintain electrical neutrality, one proton per electron emitted is exchanged through the cation-permeable membrane from the catholyte to the anolyte. The electrolytes are continuously pumped between tank and stack until the charging operation is completed. The electrolyte colours change from green $\left(V^{3+}\right)$ to purple $\left(V^{2+}\right)$ and from blue $\left(V^{4+}\right)$ to yellow $\left(\mathbb{V}^{5+}\right)$..

During discharging operation (Figure 4, right), the flow of electrons is reversed, the electrons are removed from the anolyte and transferred through the external circuit to the catholyte. The reduction is taking place in the catholyte and the oxidation in the anolyte. The reaction equations can be formulated as follows [9]:

$$
\begin{aligned}
& \text { - pole: } \mathrm{V}^{3+}+\mathrm{e}^{-} \underset{\text { discharge }}{\stackrel{\text { charge }}{\rightleftarrows}} \mathrm{V}^{2+}
\end{aligned}
$$

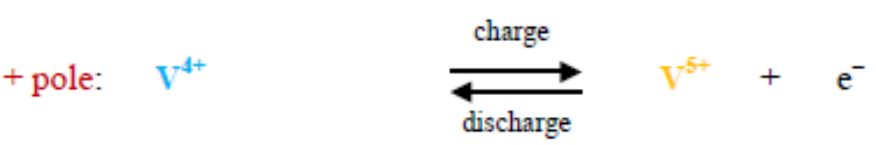
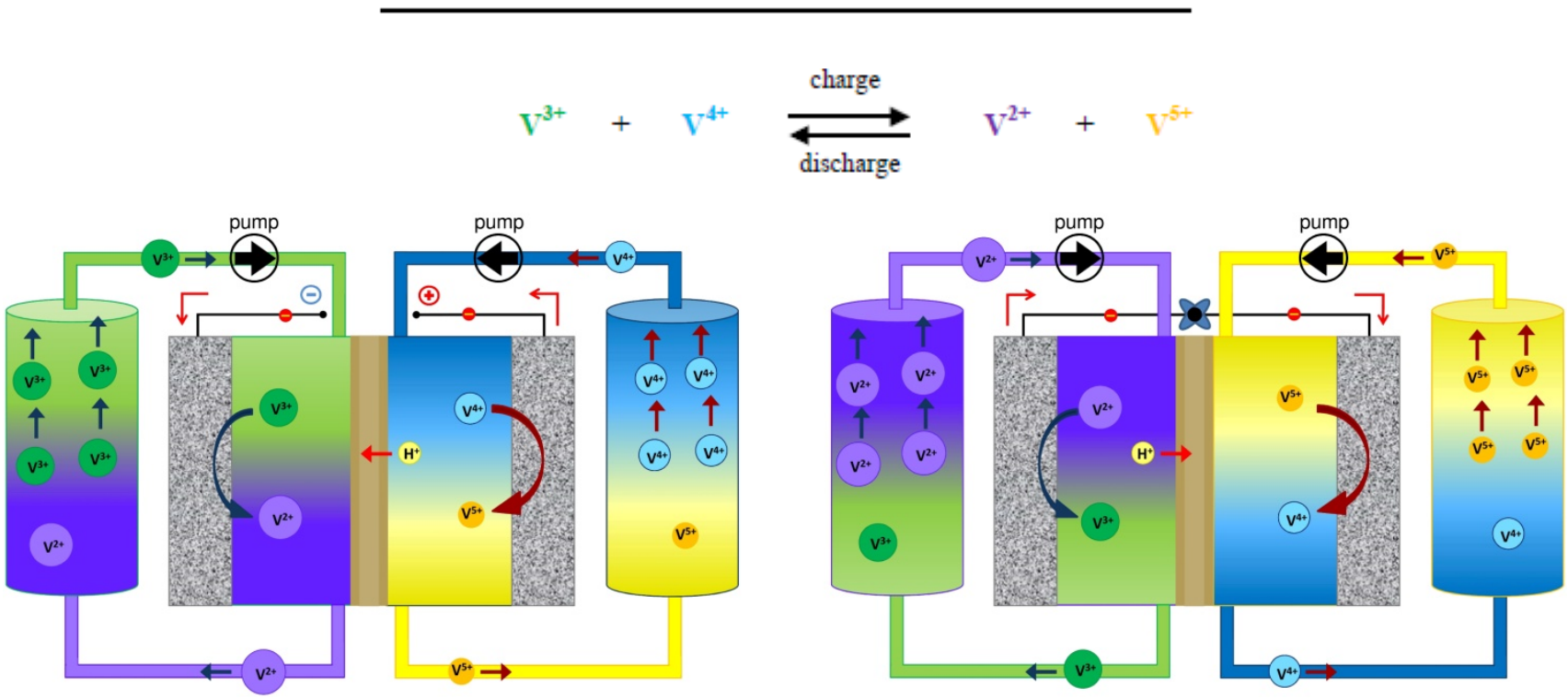

Figure 4. Left: Charging operation of a vanadium-based redox flow battery; right: discharging operation of a vanadium-based redox flow battery 


\subsection{Hybrid Flow Batteries}

Although the vanadium redox flow battery offers the advantage of using the electrolyte for an indefinite time despite the cross-contamination, this battery also has some disadvantages, such as the accumulation of compounds within the pores or on the surface of the membrane which develop by interactions between the electrolyte and the membrane (= process of fouling) [10].

In addition, $\mathbb{V}^{5+}$-ions have such a strong oxidising effect that they oxidise water molecules and as a result the $V^{5+}$-ions can "undergo thermal precipitation to form $\mathrm{V}_{2} \mathrm{O}_{5}$ " [11]. Apart from all those facts, the specific energy is "limited by the solubilities of the different vanadium ions in the temperature range of 10 to $40{ }^{\circ} \mathrm{C}$ " [11] - that requires additional temperature regulation of the system.

Besides, vanadium compounds are toxic, harmful to the environment, hardly suitable for use in schools, the worldwide occurrence of vanadium minerals is limited, and the extraction of vanadium is costly. For all these reasons, research is being carried out to find possible alternative redox couples for redox flow batteries. Since there are only a few electroactive substances in dissolved form which have a negative standard electrode reduction potential, another category of redox flow battery has been developed where a chemical specie is deposited as metal in the electrochemical cell during the charging operation. These kind of flow cells are also known as hybrid flow batteries. An example of hybrid flow batteries includes the zinc-cerium system [12].

\subsection{Redox Flow Batteries for Teaching}

The cell design of a redox flow battery is at first quite complex for use in schools. Additionally, as shown above, electrodes with high specific surface areas are required for complete oxidation or reduction of an anolyte/catholyte - with "normal" electrodes from school, the charging/discharging times are far too long.

So how can the promising topic of redox flow batteries be made accessible for teaching in schools? The authors' goal is to develop a redox flow battery that is based on inorganic substances that are harmless in terms of danger and have a different colour in the oxidised state than in the reduced one. In this way, the operating principle of a redox flow battery could be impressively demonstrated by changing the property of the electrolytes at the phenomenological level.

Electrolytes based on the four oxidation states of vanadium have different colours. However, the health hazards associated with exposure to vanadium - depending on its oxidation state - prohibit its use in schools. Electrolytes based on iron and cerium are much more suitable. In contrast to $\mathrm{Fe}^{2+}$-ions, $\mathrm{Fe}^{3+}$-ions form a red coloured complex in combination with thiocyanate ions, and a cerium solution changes its colour from yellow to colourless when reducing $\mathrm{Ce}^{4+}$ to $\mathrm{Ce}^{3+}$.

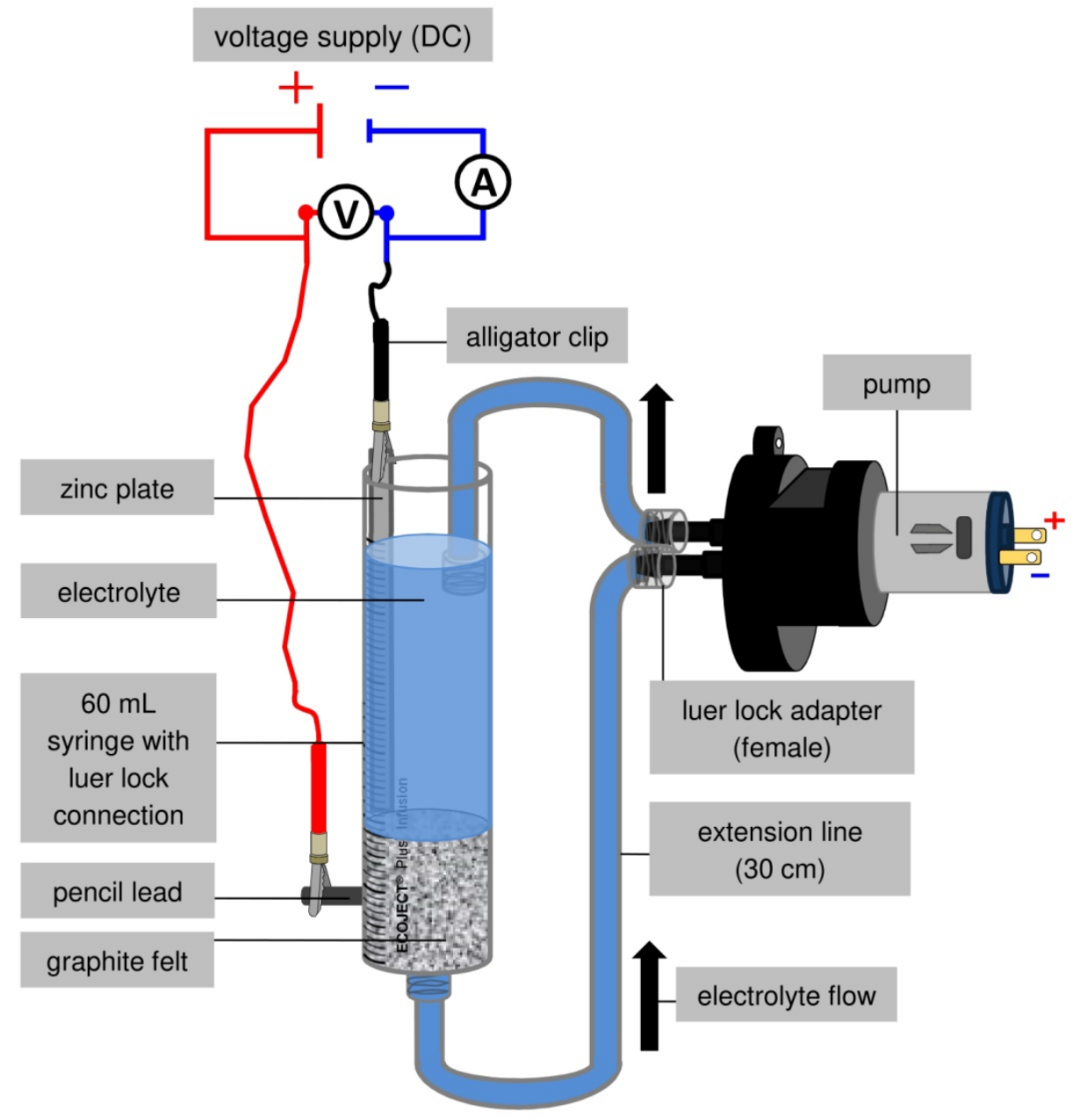

Figure 5. Freiburg's hybrid flow battery design 
To make the design as simple as possible, the focus is at first placed on hybrid flow batteries since the anode can consist of metal electrodes that are already used in chemistry lessons. Overall, materials from medical technology have proven to be suitable for a school-friendly experimental setup of a hybrid flow battery. The advantage of using these materials is that an efficient electrolyte flow can easily be generated.

Due to a direct reaction of the anode with the catholyte in the hybrid flow battery, they are usually separated from each other by a membrane to prevent capacity loss. Without a separator, the reaction in a $\mathrm{Zn}-\mathrm{Fe}^{3+}$-hybrid flow battery between $\mathbf{F e}^{3+}$-ions and elemental zinc would take place directly and the battery would thus discharge itself. In Freiburg's hybrid flow system, self-discharge can be reduced by using zinc electrodes with a small surface area (e. g. a zinc plate). Such membrane-less hybrid flow batteries are also being discussed for commercial use and because of this intensively researched [13].

With these considerations, an experimental setup is designed which is shown in Figure 5. The reaction vessel is a plastic syringe $(60 \mathrm{~mL})$ in which the electrolyte circulates through a graphite felt (SGL Carbon, type: GFA $6 \mathrm{E} \mathrm{A} ; 4 \mathrm{~cm} \cdot 19 \mathrm{~cm}$ ) with the help of a pump. The graphite felt is electrically contacted from the outside with a pencil lead. A zinc plate is connected as the - pole and the pencil lead as the + pole.

\section{Experiments}

\subsection{Hybrid Flow Battery Based on Zinc/Iron $\left(\mathrm{Zn} / \mathrm{Zn}^{2+} / / \mathrm{Fe}^{3+} / \mathrm{Fe}^{2+}\right)$}

\subsubsection{Ferric Thiocyanate Complex}

\section{Materials and chemicals}

Freiburg's hybrid flow battery design (Figure 5), voltmeter, ammeter, connection cables, $2 \mathrm{x}$ voltage supply $(1 \mathrm{x}$ with at least 3 A power), alligator clips, zinc plate $(1 \mathrm{~cm} \cdot 10 \mathrm{~cm})$, $20 \% \mathrm{H}_{2} \mathrm{SO}_{4}$ (GHS05 - corrosive effect), $\mathrm{FeSO}_{4} \cdot 7 \mathrm{H}_{2} \mathrm{O}$ (GHS07 - irritant), $\mathrm{ZnSO}_{4} \cdot 7 \mathrm{H}_{2} \mathrm{O}$ (GHS05 - corrosive effect; GHS07 - harmful; GHS09 - hazardous to water), sodium thiocyanate (GHS07 - irritant), electrical device (e. g. propeller).

\section{Procedure}

The electrolyte $(100 \mathrm{~mL})$ used is a slightly acidified (5 mL) $0.1 \mathrm{M} \mathrm{FeSO}_{4}$ solution mixed with $1 \mathrm{~g}$ sodium thiocyanate and $0.1 \mathrm{M} \mathrm{ZnSO}_{4}$. As soon as the battery is charged $(2.4 \mathrm{~V})$, a red colouration of the electrolyte can immediately be detected (Figure 6, left); accordingly, an equally rapid decolouration is observed during the discharging operation (Figure 6, right). The current of the battery during charging and discharging is approx. $140 \mathrm{~mA}$ and a terminal voltage of $1.28 \mathrm{~V}$ has been

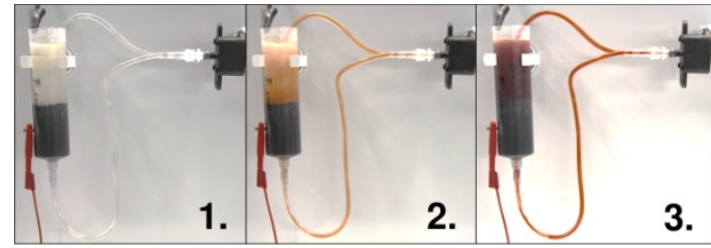

measured. This battery is extremely powerful for school purposes. The efficiency of the battery can be determined by integrating a current-time curve. Neglecting the current for the pump, a charge efficiency of $99.2 \%$ can be calculated despite self-discharge due to the direct contact between anode and catholyte.

With this first experiment, a cost-effective and methodologically convincing hybrid flow battery is presented: It is possible to classify the state of charge of the battery according to the colour changes of the electrolyte. Due to the efficient experimental setup, the battery can be charged and discharged in a short time with enough current densities. The associated colour changes of the electrolyte occur within a few seconds/minutes.

\subsubsection{Fe(III)-salicylic Acid Complex}

\section{Materials and chemicals:}

Freiburg's hybrid flow battery design (Figure 7 with a zinc plate formed as ring in the syringe), voltmeter, ammeter, connection cables, $2 \mathrm{x}$ voltage supply $(1 \mathrm{x}$ with at least 3 A power), alligator clips, zinc plate $(1 \mathrm{~cm} \cdot 10 \mathrm{~cm})$, $\begin{array}{llllll}\mathrm{FeSO}_{4} \cdot 7 & \mathrm{H}_{2} \mathrm{O} & \text { (GHS07 } & \text { - irritant), } & \mathrm{ZnSO}_{4} \cdot 7 & \mathrm{H}_{2} \mathrm{O}\end{array}$ (GHS05 - corrosive effect; GHS07 - harmful; GHS09 hazardous to water), salicylic acid (GHS05 - corrosive effect; GHS07 - irritant), electrical device (e. g. propeller).

\section{Procedure:}

The electrolyte $(100 \mathrm{~mL})$ used is a $0.1 \mathrm{M} \mathrm{FeSO}_{4}$ solution mixed with $0.1 \mathrm{M} \mathrm{ZnSO}_{4}$ and approx. $0.03 \mathrm{~g}$ salicylic acid. The mixture needs to be stirred at a higher temperature since salicylic acid does not dissolve well in cold water. The battery is discharged by an electrical device or by short-circuit current and then charged at $2.4 \mathrm{~V}$ for two to three minutes. When discharging, the pump can also remain switched off for approx. 30 seconds to make the colour change even more visible when the pump is switched on again. The battery has a terminal voltage of $1.3 \mathrm{~V}$. During discharging operation by short-circuit current, the current is approx. $90 \mathrm{~mA}$ and a discolouration of the electrolyte can be detected after only 60 seconds (Figure 8, left). After 30 seconds of charging, the iron solution already has an intense violet colour and the initial currents are $110 \mathrm{~mA}$ (Figure 8, right).

However, the voltage of these hybrid flow batteries based on iron of $1.3 \mathrm{~V}$ is of course relatively low compared to lithium-based systems in organic electrolytes $(3.5 \mathrm{~V})$. For this reason, hybrid flow batteries based on cerium ions and elemental zinc are also researched. The advantage of the redox couple $\mathrm{Ce}^{4+} / \mathrm{Ce}^{3+}$ is the higher standard electrode potential, which lies between $+1.28 \mathrm{~V}$ and $+1.72 \mathrm{~V}$ [14]. The authors therefore tested whether the zinc/cerium hybrid flow battery could also be realised in this way. The experimental setup is identical to that of the previous experiment in 2.1.1 (Figure 5). A zinc plate is connected as - pole and the pencil lead as + pole.

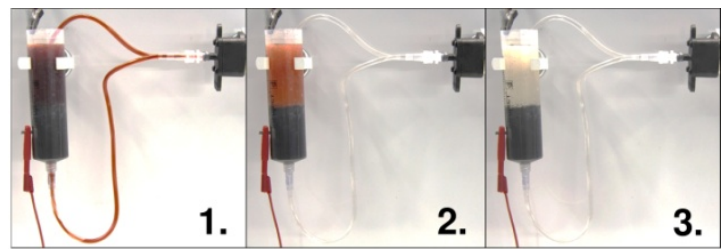




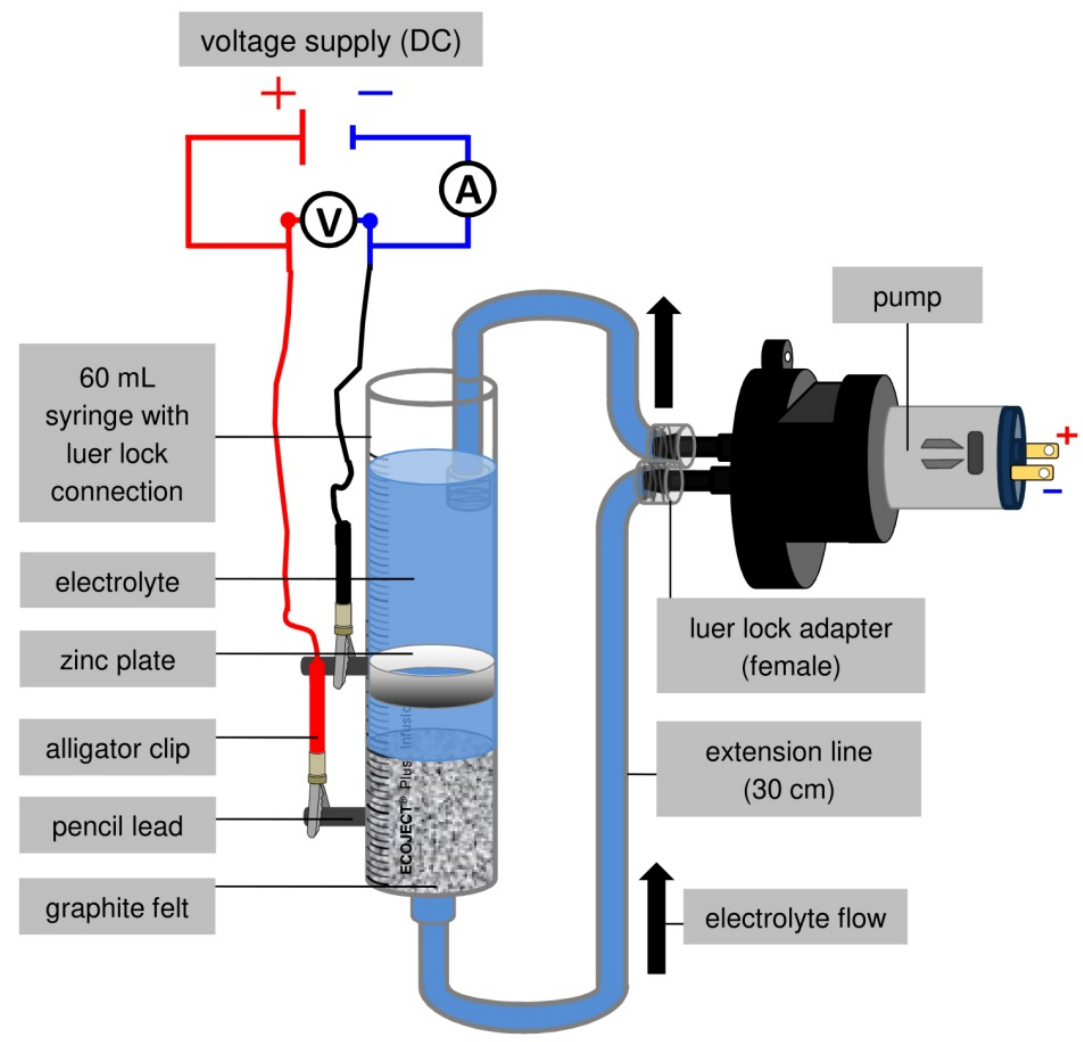

Figure 7. Freiburg's hybrid flow battery design with a zinc plate formed as ring in the syringe

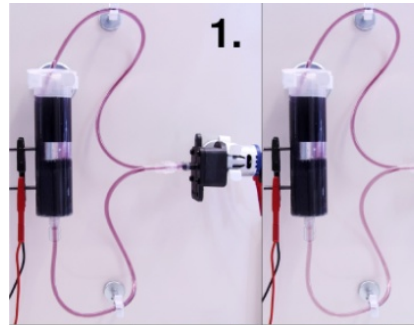

4.

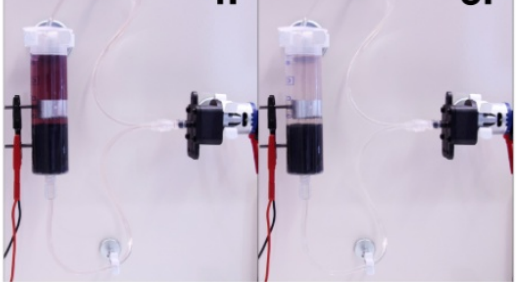

3.

2.

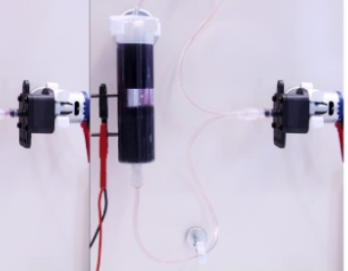

5.

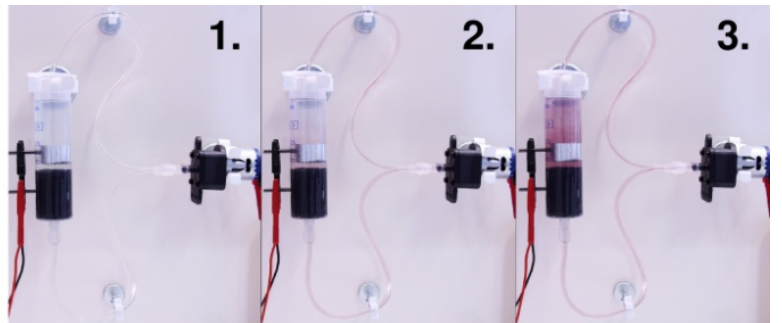

4.

5.

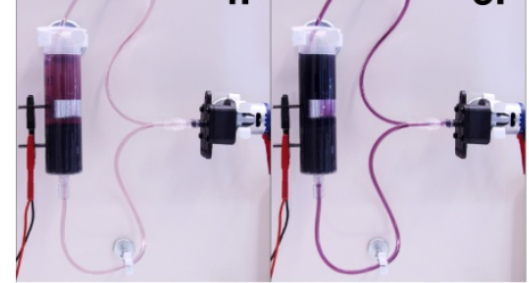

Figure 8. Reversible colour changes of another iron-based hybrid flow battery; left: discharging, right: charging

\subsection{Hybrid Flow Battery Based on Zinc/Cerium $\left(\mathbf{Z n} / \mathbf{Z n}^{2+} / / \mathrm{Ce}^{4+} / \mathbf{C e}^{3+}\right)$}

\subsubsection{Materials and Chemicals}

Freiburg's hybrid flow battery design (Figure 5), voltmeter, ammeter, connecting cables, $2 \mathrm{x}$ voltage supply (1x with at least $3 \mathrm{~A}$ power), alligator clips, zinc plate $\left(1 \mathrm{~cm} \cdot 10 \mathrm{~cm}\right.$ ), $20 \% \mathrm{H}_{2} \mathrm{SO}_{4}$ (GHS05 - corrosive effect), $\mathrm{Ce}_{2}\left(\mathrm{SO}_{4}\right)_{3} \cdot \mathrm{x} \mathrm{H}_{2} \mathrm{O}$ (GHS07 - harmful), $\mathrm{ZnSO}_{4} \cdot 7 \mathrm{H}_{2} \mathrm{O}$ (GHS05 - corrosive effect; GHS07 - harmful; GHS09 hazardous to water), electrical device (e. g. propeller).

\subsubsection{Procedure}

The electrolyte $(100 \mathrm{~mL})$ used is a slightly acidified
(6 mL) $0.08 \mathrm{M} \mathrm{Ce}_{2}\left(\mathrm{SO}_{4}\right)_{3}$ solution mixed with $0.1 \mathrm{M}$ $\mathrm{ZnSO}_{4}$. During the charging operation a yellowing of the electrolyte can quickly be detected (Figure 9, left), and during the discharging operation an equally fast decolouration gets visible (Figure 9, right). The current of this battery is approx. $150 \mathrm{~mA}$ during the charging and $260 \mathrm{~mA}$ during the discharging cycle. The system's terminal voltage is about $2.1 \mathrm{~V}$.

\subsection{Hybrid Flow Battery "to go"}

A hand pump was integrated into the modified experimental setup (Figure 10) to facilitate the circulation of the electrolyte and a $3 \mathrm{~V}$ button cell is used as voltage supply so that learners can carry out the experiment themselves. 

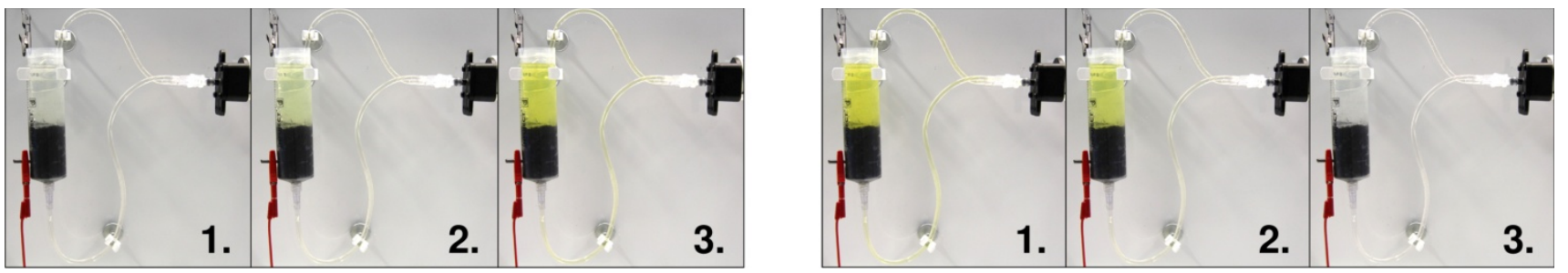

Figure 9. Reversible colour changes of a cerium-based hybrid flow battery; left: charging, right: discharging

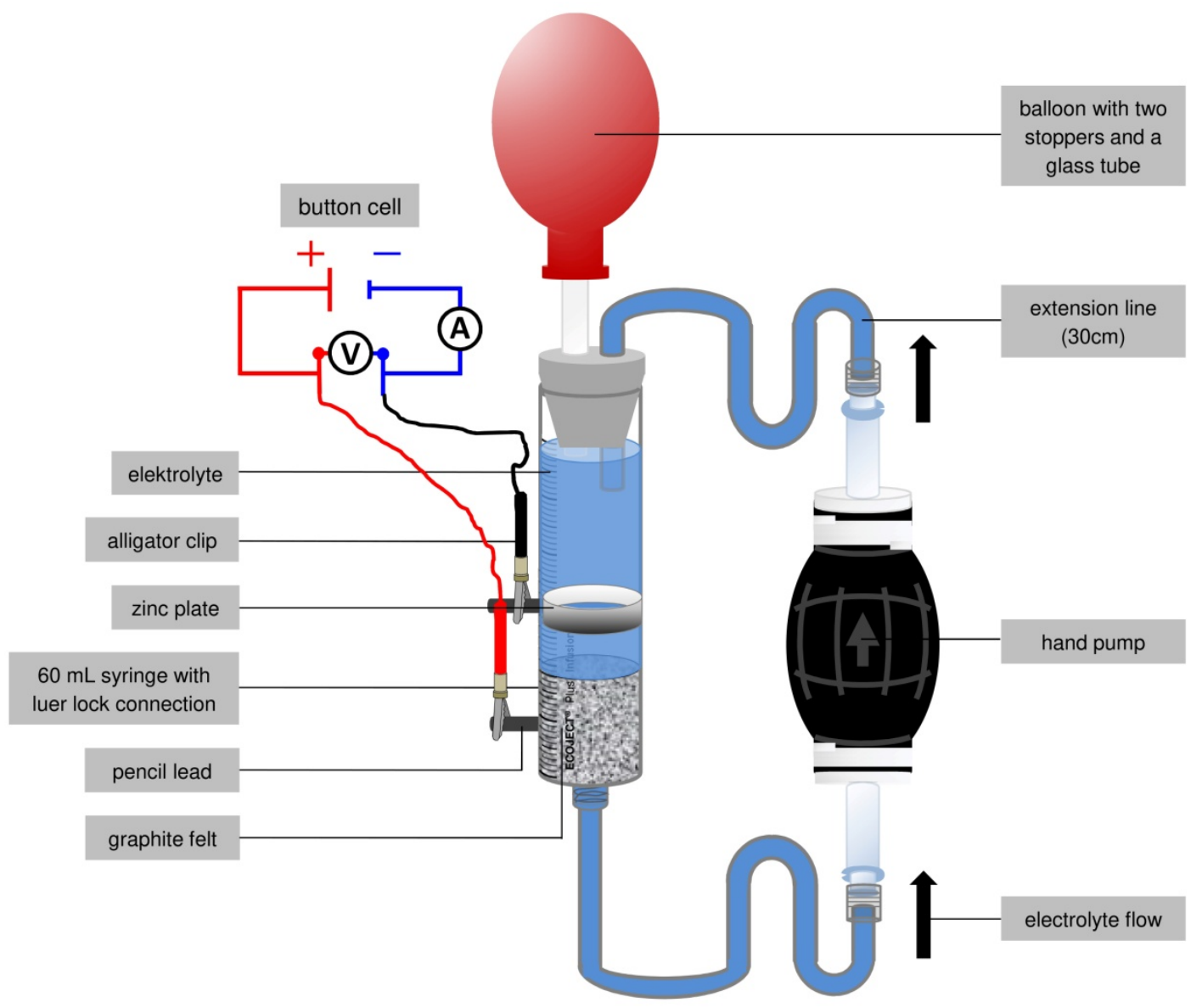

Figure 10. Experimental setup for Freiburg's hybrid flow battery "to go"

\subsubsection{Materials and Chemicals}

Freiburg's hybrid flow battery design (Figure 7 with a zinc plate formed as ring in the syringe), $2 x$ hose made of PVC, 2x female luer lock adapter, hand pump (Surepromise company, $6 \mathrm{~mm}$, e. g. Amazon; $€ 7.99$ ), lithium button cell, buzzer (https://www.reichelt.de/miniatur-summer-24vsummer-3v-p19864.html?\&trstct=pol_0), 2x short nail, pliers, alligator clips, $2 \mathrm{x}$ stopper, coin cell holder or optionally a scrunchy, balloon, glass tube, metal rod, zinc plate $(1 \mathrm{~cm} \cdot 10 \mathrm{~cm}), \mathrm{FeSO}_{4} \cdot 7 \mathrm{H}_{2} \mathrm{O}$ (GHS07 - irritant), $\mathrm{ZnSO}_{4} \cdot 7 \mathrm{H}_{2} \mathrm{O}$ (GHS05 - corrosive effect; GHS07 harmful; GHS09 - hazardous to water), sodium thiocyanate (GHS07 - irritant).

\subsubsection{Procedure}

The electrolyte $(100 \mathrm{~mL})$ used is a $0.1 \mathrm{M} \mathrm{FeSO}_{4}$ solution mixed with $2 \mathrm{~g}$ sodium thiocyanate and $0.1 \mathrm{M}$ $\mathrm{ZnSO}_{4}$. Figure 11 shows the material required for the hybrid flow battery "to go" - the coin cell holder can also be replaced by a scrunchy.

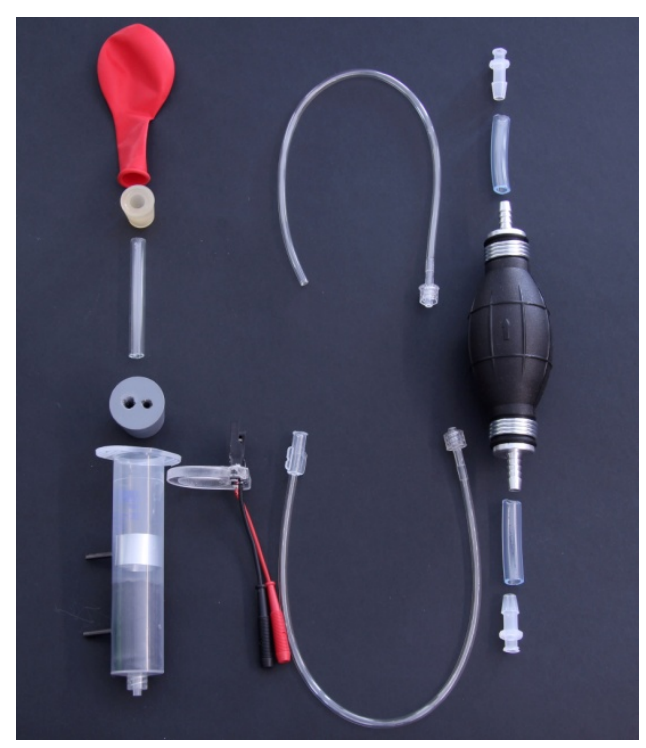

Figure 11. Required material for the construction of a hybrid flow battery "to go" 

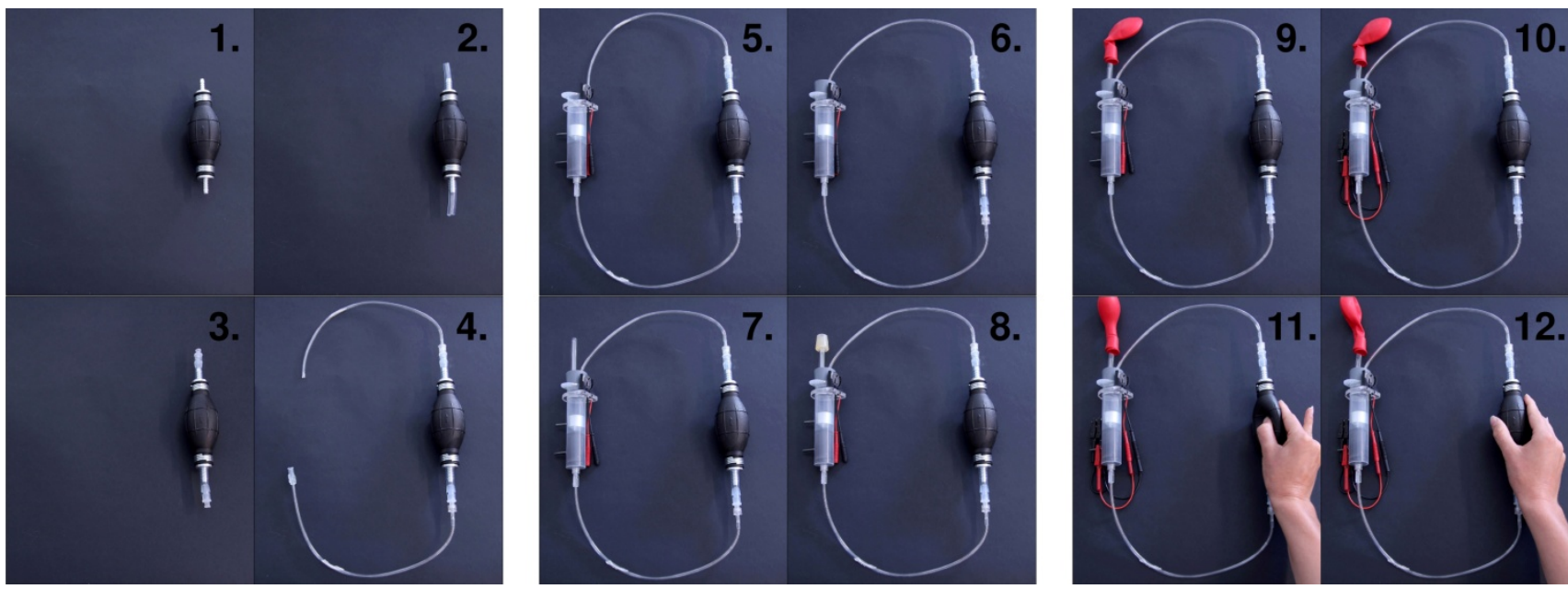

Figure 12. Construction of Freiburg's hybrid flow battery "to go" (left: 1.-4., middle: 5.-8., right: 9.-12.)

In a first step, the hand pump (Figure 12, 1.) must be put together. Make sure that the arrow on the hand pump points upwards as shown in the figures. First push two hoses made of PVC (approx. $4 \mathrm{~cm}$ long) onto the ends of the hand pump (Figure 12, 2.). These ensure that the extension lines can tightly be connected to the hand pump via female luer lock adapters. The two adapters must be pushed into the hoses as far as possible (Figure 12, 3.). The extension lines can then be screwed onto the adapters (Figure 12, 4.). As soon as these are attached to the hand pump, the end piece of the upper extension line is cut off.

Once the hand pump is put together, the rest of the experimental setup needs to be done. To do this, take a Freiburg's hybrid flow battery design (with a zinc plate formed as ring in the syringe) onto which the coin cell holder with a $3 \mathrm{~V}$ button cell is pushed before (!) contacting the electrodes with the pencil leads (Figure 12,5.). The next step is to take a stopper with two holes through which the cut off end of the upper extension line is inserted into the right hole (tip: With the help of a thin metal rod, the extension line can be inserted through the hole without bending it over). You must make sure that the hole is as small as necessary: After all, the battery system must be so tight that it can also be laid down on the table with the electrolyte contained in it. The stopper with the extension line can then be placed on the syringe (Figure 12,6.). A glass tube (approx. $5 \mathrm{~cm}$ long) is inserted into the second hole of the stopper - the hole should also fit as accurately as possible here. The glass tube should only be inserted into the stopper, it does not have to be guided completely through it (Figure 12, 7.). Slide another single drilled stopper onto this glass tube (Figure 12, 8.).

To allow the system both to equalise the pressure and to seal it tightly, a balloon is attached to the stopper on the glass tube (Figure 12, 9.). Finally, the coin cell holder with the button cell must be contacted with the pencil leads on the syringe using alligator clips. The - pole is connected to the zinc plate, the + pole to the graphite felt (Figure 12,10.). As soon as the hand pump is compressed, the balloon inflates (Figure 12,11.). When the hand pump is released, the balloon becomes limp again (Figure 12, 12.).

\section{Scrunchy as coin cell holder:}

As already mentioned at the beginning of this chapter, it is also possible to do the experimental setup without the coin cell holder for the button cell. A scrunchy serves as a cheap replacement. To get the button cell properly contacted, it is important that the alligator clips are insulated on one side of the clips. This can be achieved e. g. with an adhesive tape that is wrapped around one side of the clip for several times. A scrunchy is then taken and stretched so often around the syringe between the pencil leads that it does not slip away. The clips are placed close to each other underneath the scrunchy so that they are also firmly attached to the syringe. Finally, the button cell is inserted into the clips, making sure that one insulated side is on the + pole and the other insulated side is on the - pole. It is important not to unintentionally provoke a short-circuit: Thorough insulation of the clips is indispensable! The experimental setup looks as follows (Figure 13):

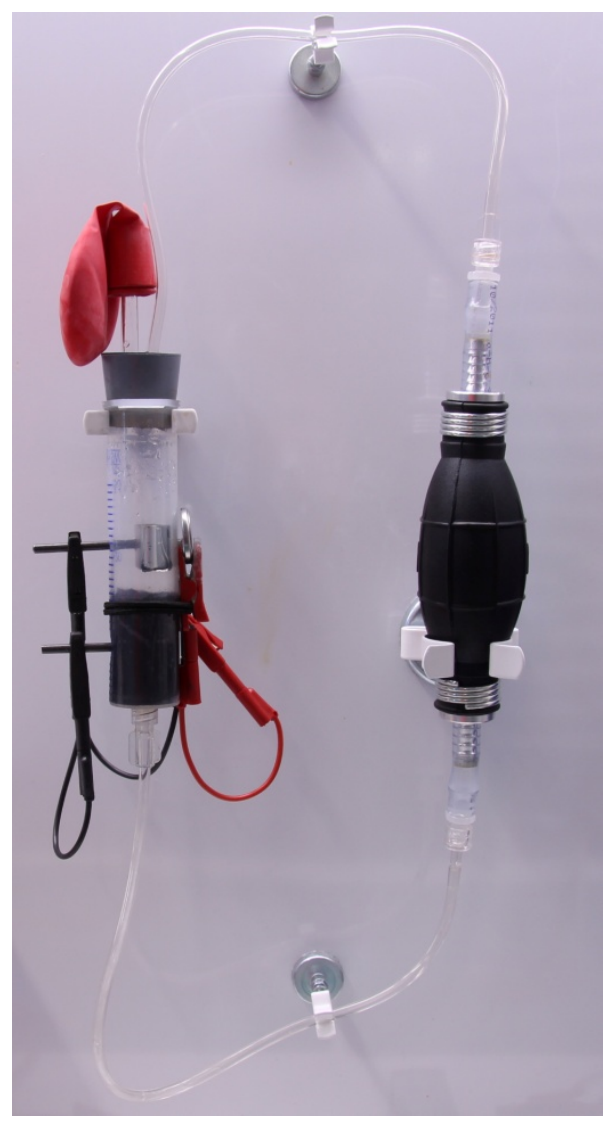

Figure 13. Experimental setup of the hybrid flow battery "to go" with a scrunchy 

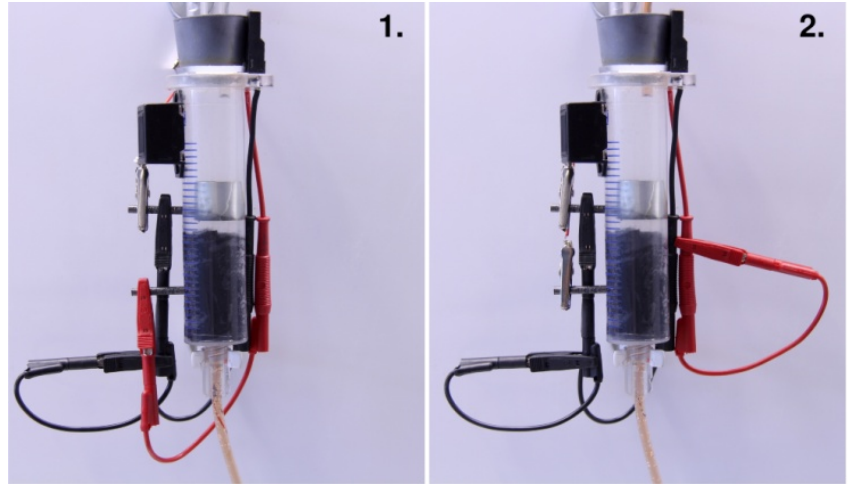

2.

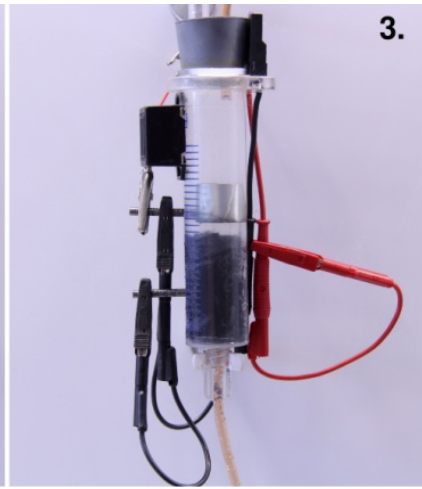

Figure 14. Freiburg's hybrid flow battery to go (left: charging; middle: discharging via buzzer; right: discharging via short-circuit)

\section{Coin cell holder with a buzzer:}

The electrolyte is filled into the syringe by removing the lower extension line at the end of the syringe and holding it in the container with the electrolyte solution. The hand pump is then compressed approx. twice so that the electrolyte is drawn up into the hand pump. The extension line can then be reattached to the syringe. You can also attach a buzzer to the syringe using two small nails. The tip of the nails in the syringe can be shortened with pliers.

The silver alligator clips are for the buzzer (- pole: zinc plate, + pole: graphite felt). The upper black alligator clip, which is connected to the - pole, always remains on this pencil lead and is not changed. The lower black alligator clip (not connected with a pencil lead) is the - pole of the button cell, the red alligator clip is the + pole of the button cell. To charge the system, first remove the lower silver clip, so that the electrical circuit of the buzzer is no longer closed. Afterwards, take the red clip and attach it to the lower pencil lead (Figure 14, left). If you start pumping the electrolyte through the syringe, the battery is charged.

As soon as the battery is charged, the buzzer can be reconnected. The first step is to remove the red clip so that the electrical circuit of the button cell is no longer closed. Then take the lower silver clip and attach it to the lower pencil lead again (Figure 14, middle). The buzzer's electric circuit is thus closed and as soon as the electrolyte flow is started via hand pump, you should be able to hear the buzzer.

If the discharging operation via buzzer takes too long, a short-circuit can also be connected. To do this, remove the lower silver clip of the buzzer. This means that both the electrical circuit of the button cell and that of the buzzer are no longer closed. In a next step, take the black lower clip and attach it to the lower pencil lead. This directly connects the -pole (upper black clip) and the + pole (lower black clip), resulting in a short-circuit (Figure 14, right). If the hand pump is compressed again, the discharging operation now takes place through a short-circuit current.

\section{Observations:}

After compressing the hand pump two or three times, a distinct red colouration of the electrolyte can be seen (Figure 15). After further, repeated pumping the iron solution shows an intense red colour. When discharging via buzzer, a discolouration of the electrolyte can be observed after pumping five to eight times. The buzzer sounds loud, but the volume always varies, depending on how much electrolyte has been pumped into the syringe and how far the discharge process has already progressed. As soon as a short-circuit has been connected, a discolouration of the electrolyte in the lower extension line can be detected after the first compression of the hand pump (Figure 16).

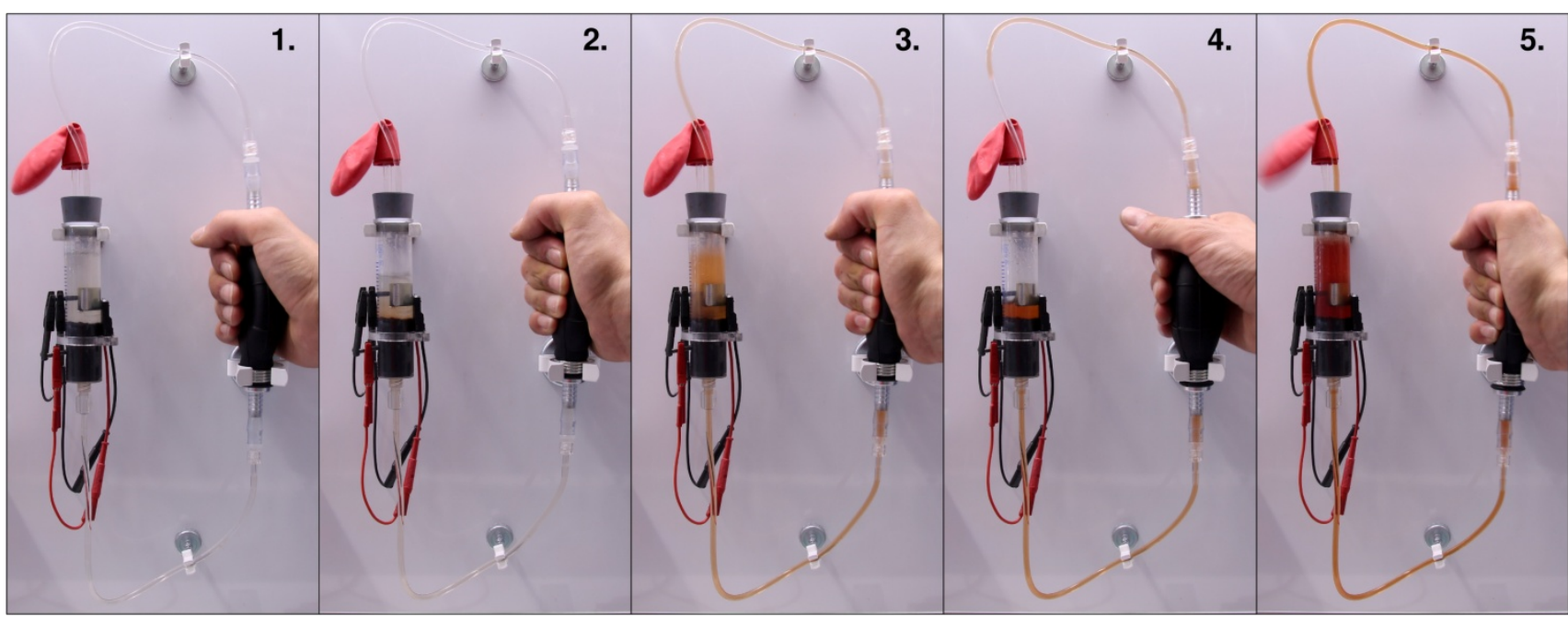

Figure 15. Charging operation with a colour change to red 


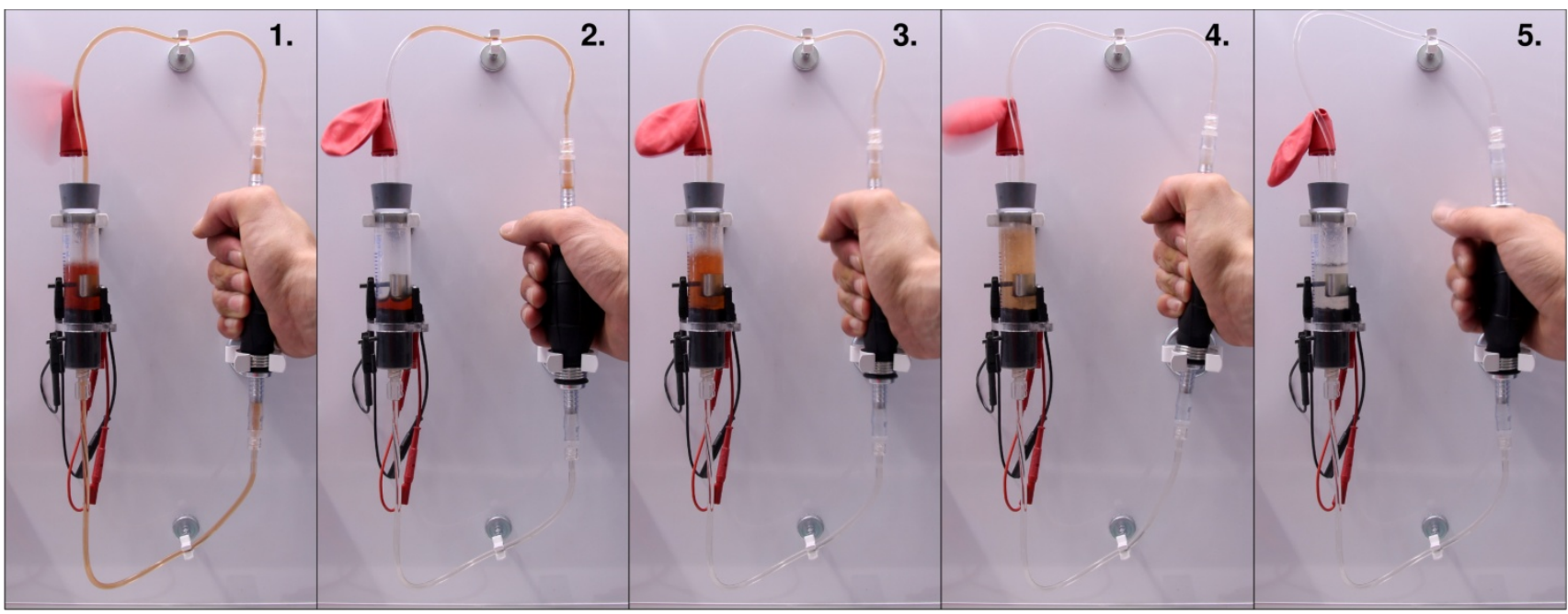

Figure 16. Discharging operation with a discolouration

\subsection{Redox Flow Battery Based on Iron/Cerium $\left(\mathrm{Fe}^{2+} / \mathrm{Fe}^{3+} / / \mathrm{Ce}^{4+} / \mathrm{Ce}^{3+}\right)$}

In redox flow batteries, the energy is stored in two electrolytes. This distinguishes the redox flow batteries from the previously introduced hybrid flow batteries, in which a part of the energy is stored in the anode material. For a redox flow battery, a membrane is almost inevitable since mixing the electrolytes would lead to a self-discharge of the battery. In this experiment, a specially manufactured redox flow battery is presented which has already been designed at the Freiburg University of Education in 2017.

\subsubsection{Materials and Chemicals}

Freiburg's redox flow battery design, graphite felt (SGL Carbon, type: GFA 6 E A; size: $6,4 \mathrm{~cm} \cdot 5,8 \mathrm{~cm}$ ), graphite foil Keratherm ${ }^{\circledR}$ (http://www.conrad.de; $2 \mathrm{x}$ foil: size: $6,4 \mathrm{~cm} \cdot 5,8 \mathrm{~cm}$ ), cation exchange membrane (fumasep cation FKB-PK-130; $110-140 \mu \mathrm{m}$; size: $8,4 \mathrm{~cm} \cdot 8,4 \mathrm{~cm})$, $2 \mathrm{x}$ syringe $(10 \mathrm{~mL})$ with luer lock connection, $6 \mathrm{x}$ extension line $(30 \mathrm{~cm})$, luer lock adapter, $2 \mathrm{x}$ pumps (modelcraft; manufacturer number: F3007; 12V; 0.6 $\mathrm{L} / \mathrm{min}$; dimensions: $70 \mathrm{~mm} \cdot 56 \mathrm{~mm} \cdot 33 \mathrm{~mm}$ ), scissors, carpet knife, alligator clips, connecting cables, $3 \mathrm{x}$ voltage supply ( $3 \mathrm{x}$ with at least $3 \mathrm{~A}$ power), $20 \% \mathrm{H}_{2} \mathrm{SO}_{4}$ (GHS05 - corrosive effect), $\mathrm{Fe}_{2}\left(\mathrm{SO}_{4}\right)_{3}$ (GHS05 - corrosive effect; GHS07 - irritant), sodium thiocyanate (GHS07 - irritant), $\mathrm{Ce}_{2}\left(\mathrm{SO}_{4}\right)_{3} \cdot \mathrm{x} \quad \mathrm{H}_{2} \mathrm{O}$ (GHS07 - harmful), $0.5 \mathrm{M} \mathrm{H}_{2} \mathrm{SO}_{4}$ (GHS05 - corrosive effect), electrical device (e. g. propeller).

\subsubsection{Procedure}

\section{Electrolyte A:}

The iron-based electrolyte $(100 \mathrm{~mL})$ used is a slightly acidified $(5 \mathrm{~mL}) 0.08 \mathrm{M} \mathrm{Fe}_{2}\left(\mathrm{SO}_{4}\right)_{3}$ solution mixed with $1 \mathrm{~g}$ sodium thiocyanate.

\section{Electrolyte B:}

The cerium-based electrolyte $(100 \mathrm{~mL})$ used is a $0.08 \mathrm{M} \mathrm{Ce}_{2}\left(\mathrm{SO}_{4}\right)_{3}$ solution. The cerium(III)-sulfate is dissolved in $0.5 \mathrm{M} \mathrm{H}_{2} \mathrm{SO}_{4}$ instead of distilled water for at least two hours.

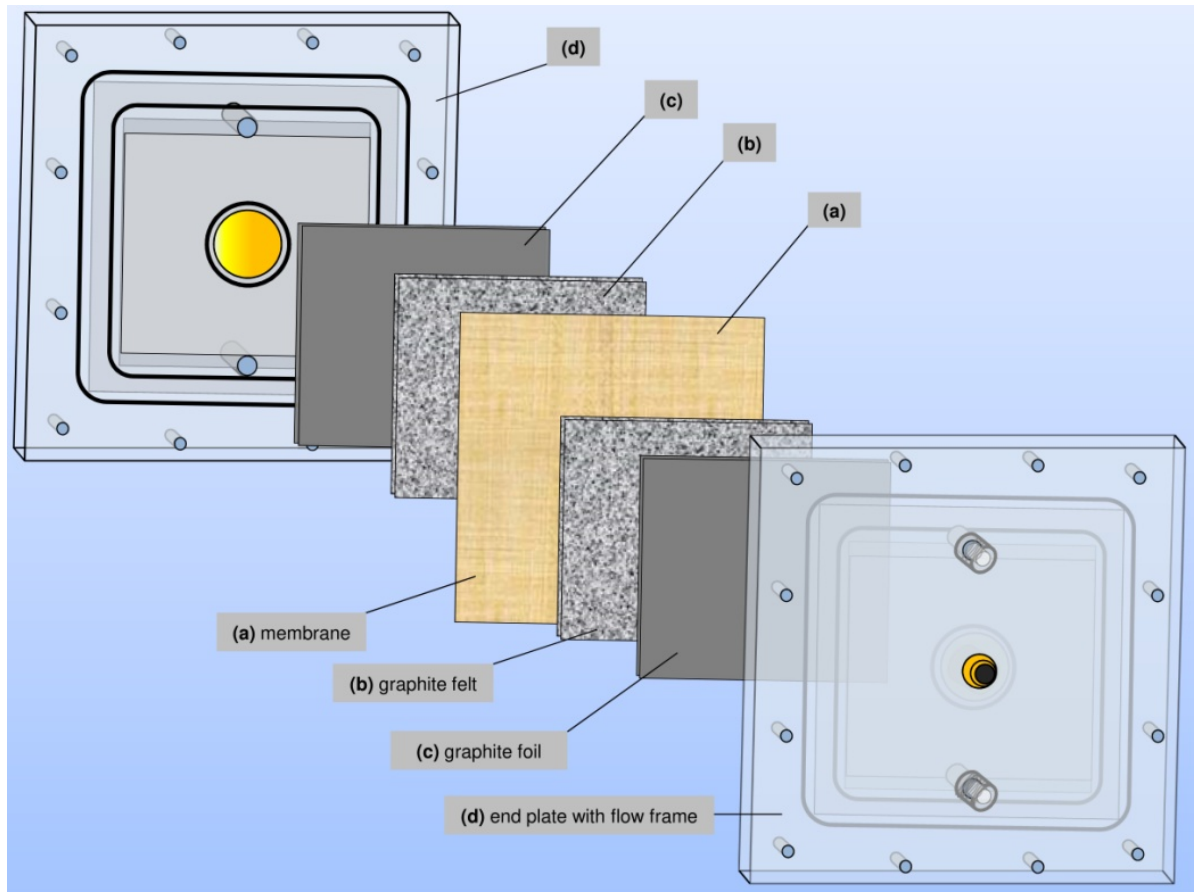

Figure 17. Components of Freiburg's redox flow battery 


\section{Experimental setup:}

The authors succeeded in designing a redox flow battery for chemistry lessons. For this purpose, the flow frame was integrated into the end plates, thus simplifying the experimental setup (Figure 17). Firstly, a graphite foil is placed in the body of the cell to prevent the electrolytes from contacting the current collector. The graphite felt is placed on top of the graphite foil and a cation-selective membrane is placed in between. Finally, the redox flow battery is fastened with wing bolts and nuts. The individual steps of the assembly are shown in Figure 18.

The experimental setup for battery operation is shown schematically in Figure 19.

The $\mathrm{Fe}_{2}\left(\mathrm{SO}_{4}\right)_{3}$ solution is electrolyte $\mathrm{A}$, while the $\mathrm{Ce}_{2}\left(\mathrm{SO}_{4}\right)_{3}$ solution is electrolyte $\mathrm{B}$. The electrolytes are added to the two syringes. The electrolyte flow corresponds to the direction shown in Figure 19 since the direction is important for optimal reduction/oxidation of the electroactive species. Therefore, the electrolyte needs to flow through the graphite felt from the bottom to the top of the cell to fill out the smallest gaps. The battery is charged at a voltage of $3 \mathrm{~V}$ and afterwards discharged via short-circuit or electrical devices. Within a few seconds, the side with the $\mathrm{Ce}_{2}\left(\mathrm{SO}_{4}\right)_{3}$ electrolyte turns yellow. After a few minutes the discolouration of the $\mathrm{Fe}_{2}\left(\mathrm{SO}_{4}\right)_{3}$ electrolyte begins (Figure 20). During a discharging cycle via short-circuit, the $\mathrm{Fe}_{2}\left(\mathrm{SO}_{4}\right)_{3}$ electrolyte changes its colour to red again within a few seconds, while the $\mathrm{Ce}_{2}\left(\mathrm{SO}_{4}\right)_{3}$ electrolyte is completely discoloured after several minutes (Figure 21).

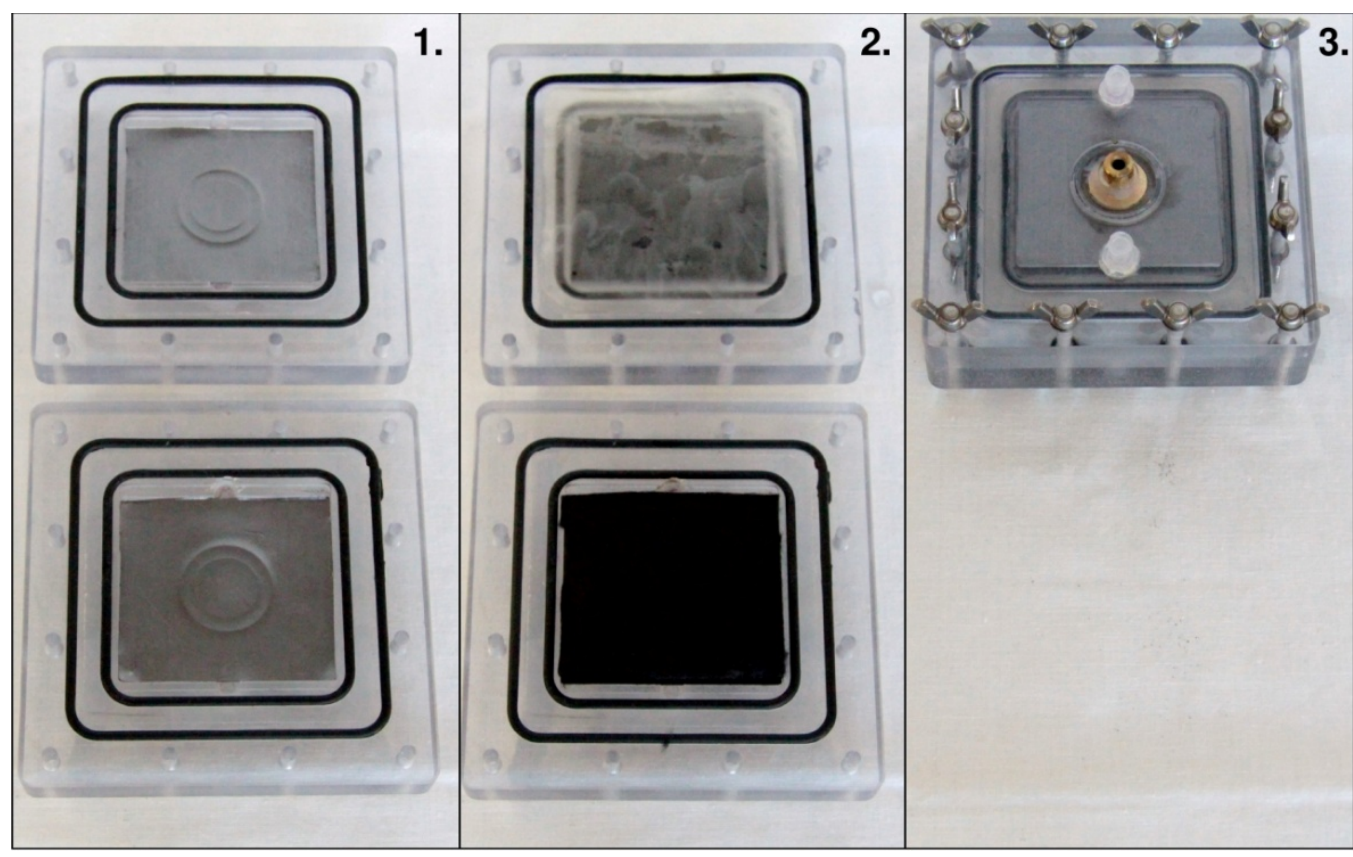

Figure 18. Individual steps for the assembly of the cell

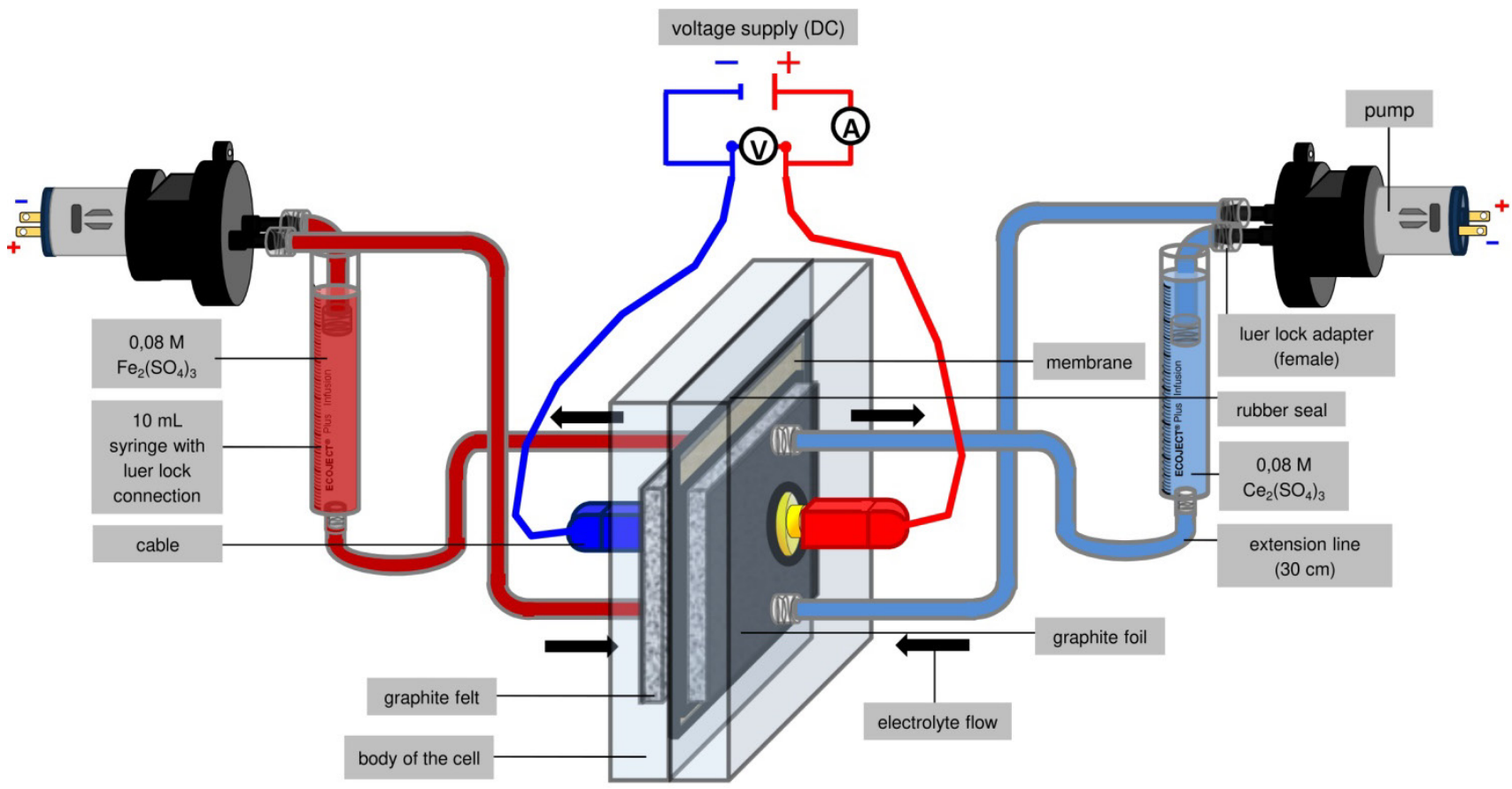

Figure 19. Experimental setup for battery operation 


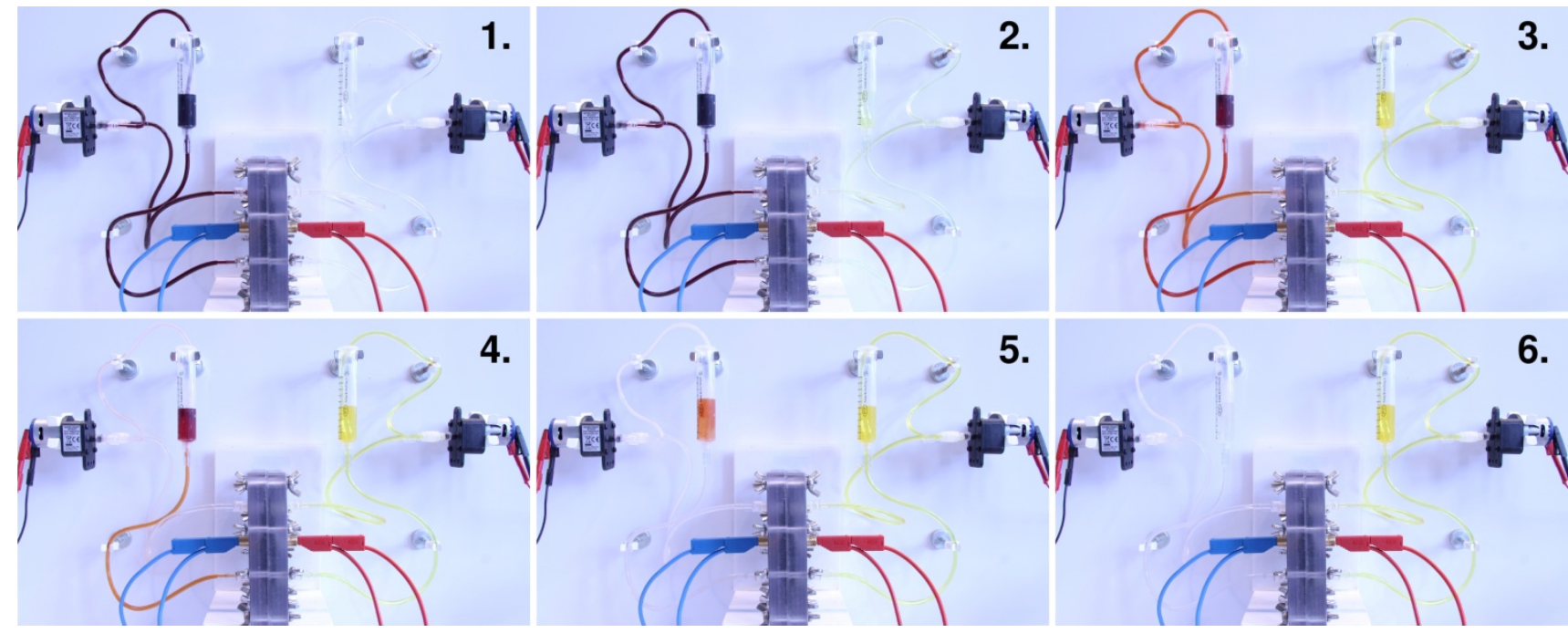

Figure 20. Charging operation of Freiburg's redox flow battery based on iron and cerium salts

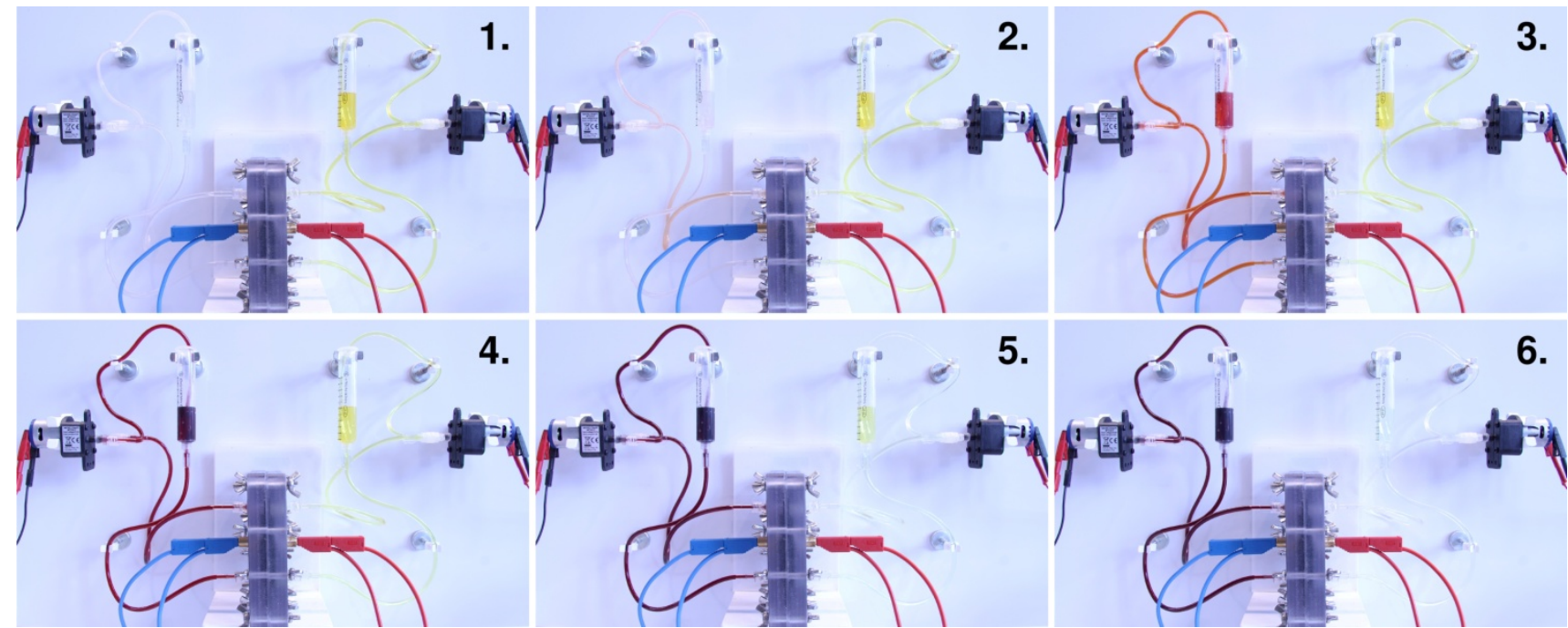

Figure 21. Discharging operation of Freiburg's redox flow battery based on iron and cerium salts

\section{Results and Discussion}

First experimental and theoretical proposals for a methodological implementation of redox flow batteries with organic substances were provided by the work of Rosenberg and Jansen [15]. However, the aim of the authors from Freiburg was to develop various hybrid flow batteries as well as a "technical" redox flow battery based on inorganic electrolytes which have a different colour in the oxidised state than in the reduced one. The authors succeeded in an extraordinary way, so that the operating principles of hybrid flow batteries and redox flow batteries could be impressively worked out with a phenomenological approach to the topic due to the colour changes of the electrolytes.

\subsection{Freiburg's Hybrid Flow Batteries}

\subsection{1. $\mathrm{Zn} / \mathrm{Zn}^{2+} / / \mathrm{Fe}^{3+} / \mathrm{Fe}^{2+}$}

During the charging operation of the hybrid flow battery based on zinc/iron in combination with sodium thiocyanate, the $\mathrm{Fe}^{2+}$-ions in the solution were oxidised to
$\mathrm{Fe}^{3+}$-ions. The electrons of the $\mathrm{Fe}^{2+}$-ions were taken up by the $\mathrm{Zn}^{2+}$-ions which were thus reduced to elemental zinc (Figure 22, left). The processes of the discharging operation were reversed (Figure 22, right). The colouration of the electrolyte was due to the fact that $\mathrm{SCN}^{-}$-ions form the $\left[\mathrm{Fe}\left(\mathrm{H}_{2} \mathrm{O}\right)_{5}(\mathrm{SCN})\right]^{2+}$-complex with $\mathrm{Fe}^{3+}$-ions, which has a characteristic red colour [7].

In comparison, the hybrid flow battery based on zinc/iron in combination with salicylic acid worked exactly like the one just explained above: As the battery was discharged, elemental zinc was oxidised to $\mathrm{Zn}^{2+}$-ions at the - pole, while $\mathrm{Fe}^{3+}$-ions were reduced to $\mathrm{Fe}^{2+}$-ions at the + pole. The processes during charging were reversed. But in this case, the discolouration of the electrolyte was due to the fact that salicylic acid forms only with $\mathrm{Fe}^{3+}$ ions the Fe(III)-salicylic acid complex, which has a characteristic violet colour.

\section{Anomalous co-deposition:}

At this point, attentive readers may be surprised that instead of iron ions - zinc ions were deposited, although the standard electrode potential of zinc is significantly lower - it is generally said that zinc is less "noble" than iron. Accordingly, iron ions should have rather taken up 
the electrons. In these systems, however, the redox processes took place with preferred separation of the less noble component, which is referred to as anomalous co-deposition. This special effect occurs only under certain electrolyte conditions and is preferred in systems with elements from the iron group. Firstly, this behaviour "... has been attributed to the so-called hydroxide suppression mechanism (HSM), wherein the formation of a surface hydroxide layer (e. g., $\mathrm{Zn}(\mathrm{OH})_{2}$ ) impedes the transport of the more noble metal ions to the underlying substrate" [16]. But the mechanism (HSM) was inconsistent with experimental data, thus the phenomenon of anomalous co-deposition could not yet be clarified scientifically, but it has been found that zinc ions contained in the electrolyte prevent the deposition of iron. There is more research needed but it is important to take advantage of this phenomenon for application in flow batteries. [16]

\subsection{2. $\mathbf{Z n} / \mathbf{Z n}^{\mathbf{2 +}} / / \mathrm{Ce}^{4+} / \mathbf{C e}^{\mathbf{3 +}}$}

The different colouration of a $\mathrm{Ce}^{3+}$-solution (colourless) and a $\mathrm{Ce}^{4+}$-solution (yellow) in addition to the high standard electrode potential turned the hybrid flow battery based on zinc/cerium into a highly interesting system as well. During charging $\mathrm{Zn}^{2+}$-ions were reduced to elemental zinc, while $\mathrm{Ce}^{3+}$ ions were oxidised to $\mathrm{Ce}^{4+}$-ions (Figure 23, left). The discharging operations were reversed (Figure 23, right). The $\mathrm{Ce}^{4+}$-ions are responsible for the yellow colour of the solution, whereas an aqueous solution of $\mathrm{Ce}^{3+}$-ions is colourless. The authors succeeded in creating a powerful hybrid flow battery with a high terminal voltage of $2.1 \mathrm{~V}$ for aqueous systems.

\subsection{3. $\mathbf{Z n} / \mathrm{Zn}^{2+} / / \mathrm{Fe}^{3+} / \mathrm{Fe}^{2+}$ "to go"}

With the aim of designing an even more pupil-oriented experiment, the authors also developed the hybrid flow battery "to go". A hand pump was integrated into the modified experimental setup to facilitate the circulation of the electrolyte and a $3 \mathrm{~V}$ button cell was used as voltage supply so that learners could carry out the experiment themselves. The processes during charging/discharging cycles of the battery were the same as for the hybrid flow battery based on zinc/iron in combination with sodium thiocyanate. Besides, no acid was used in this experimental setup and it was even tightly sealed to prevent any unpleasant odours from escaping.
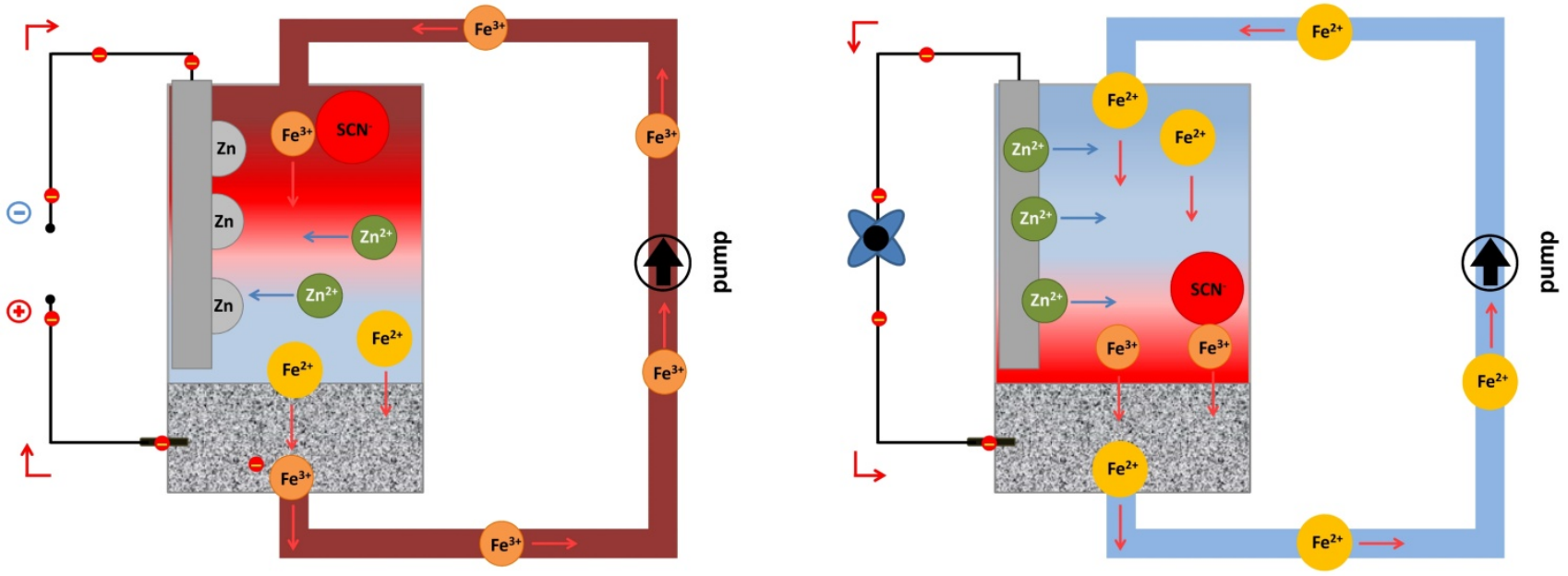

Figure 22. Processes during charging (left) and discharging (right) at the particulate level
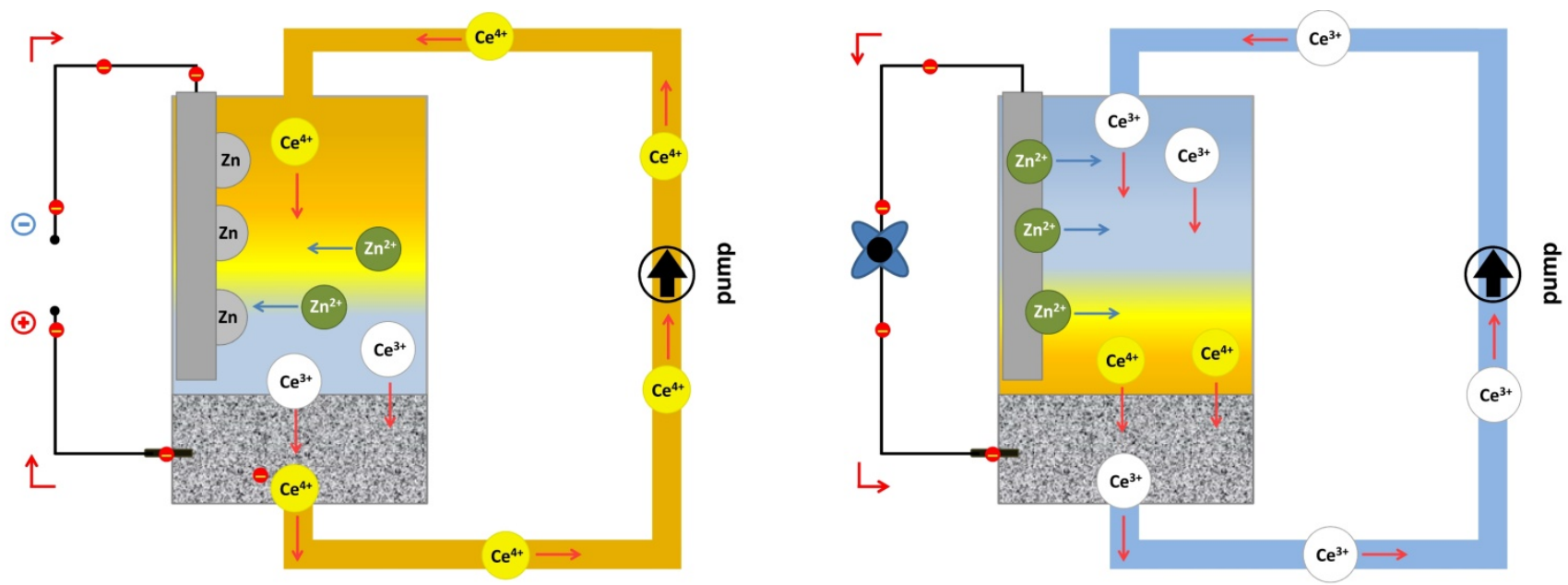

Figure 23. Processes during charging (left) and discharging (right) at the particulate level 


\subsection{Freiburg's Redox Flow Battery}

Although this redox flow battery had a cell voltage of only $0.8 \mathrm{~V}$, it was still powerful. During a charging cycle ( $3 \mathrm{~V}$ ) a current of $5 \mathrm{~A}$ could be measured and during a discharging operation approx. $2 \mathrm{~A}$. This was extraordinarily high for a school battery. The change of colour of the electrolytes also succeeded within a few minutes. The processes of charging/discharging operations (Figure 24) could be formulated as follows:
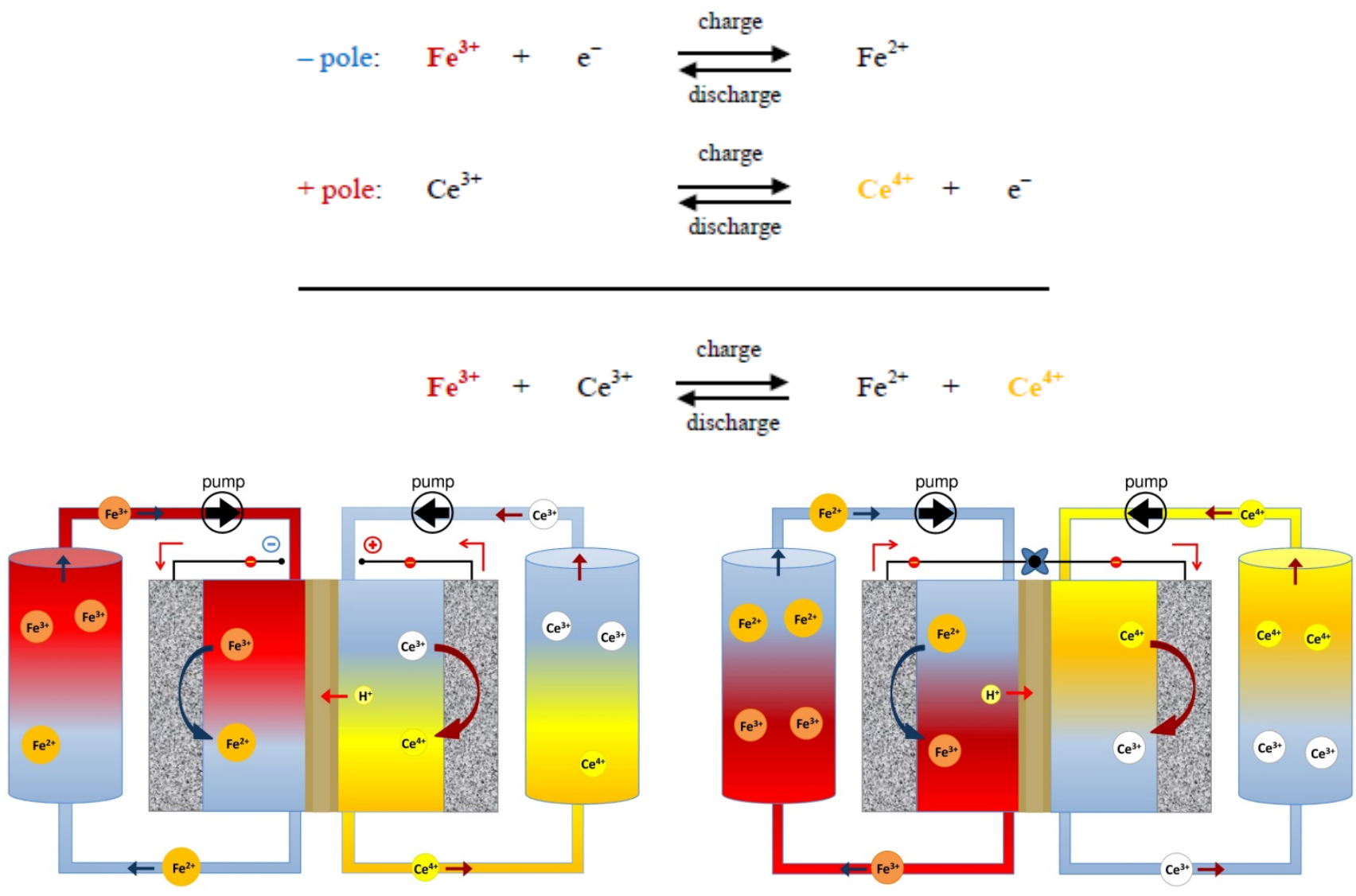

Figure 24. Processes during charging (left) and discharging (right) at the particulate level

\subsection{Energy Conversion Efficiency}

In all the experiments presented (except 2.3), the authors neglected the required pumping power when measuring the efficiency of the individual systems since mainly low-cost materials (pump: $€ 13$ ) were used for the experimental setup. If one neglects the charge loss according to the pump, the efficiencies of the different battery systems are high $(>95 \%)$ despite the selfdischarge due to the direct contact between anode and catholyte. This can be explained by the fact that during a discharging cycle, lots of zinc ions get simultaneously dissolved, so that other ions of the electrolyte have hardly any chance of reaching the anode. Compared to technical applications, it must be mentioned that the required pumping power is significantly higher than the power supplied by the battery systems itself. Thus, these newly developed experiments are only methodological model experiments for the preparation of the topic of redox flow batteries in schools and universities.

\section{Conclusions}

Due to their independent scalability of energy and power, redox flow batteries are important large-scale energy storage systems. They represent a significant building block for the success of the energy transition, as the electricity generated from renewable energy sources must be temporarily stored. So far, redox flow batteries have been a cost-effective alternative to storing energy. It is therefore essential to implement this important and forward-looking topic in the curricula of university and school education.

In this article, the authors were able to demonstrate experiments for the experimental and conceptual development of the topic of inorganic redox flow batteries at a phenomenological level. Freiburg's experimental setup with utensils from medical technology and a graphite felt as electrode material is convincing because with normal (graphite) electrodes from school, the charging/discharging times are too long for practical usage: For a complete oxidation or reduction of an anolyte/catholyte electrodes with high specific surface areas are required since the ions which need to be converted must diffuse to the electrodes.

Apart from the experimental setup, another interesting inorganic hybrid flow battery is based on zinc and iodine. Zinc and iodine are not only known to the students from everyday life: They are used in a variety of scientific subjects. The repeated use of these two substances as electroactive species in a hybrid flow battery follows the methodological principle of a spiral curriculum by 
activating knowledge from previous lessons and thus incorporating the students' ideas.

The authors achieved many other pleasing results, such as the realisation of several organic hybrid flow batteries (with e. g. anthraquinone-2-sulfonic acid sodium salt) [17]. Besides, redox indicators such as methylene blue, safranin, alizarin or indigo carmine also have a different colour in the oxidised state than in the reduced one [18]. They are interesting for hybrid flow batteries not only because of their colour, but also because oxygen can oxidise them. The authors' idea was to oxidise these systems (i. e. to convert them to a charged state) with atmospheric oxygen using a slightly modified experimental setup.

In addition to the systems already mentioned, it is often important for teachers to work with substances that can be procured quickly and inexpensively. Therefore, some systems based on ink cartridges (which often contain triarylmethane dyes) or dyes contained in food (e.g. M\&M's) or beverages (e.g. Blue Curaçao, wine) such as Brilliant Blue FCF or malvidin were developed in Freiburg [19].

Furthermore, the authors have already presented the design of a hybrid flow battery with an integrated, separate tank to show learners the advantage of the independent scalability of energy and power of redox flow batteries.

By conducting some of these experiments, students not only improve their experimental skills, but also learn fundamental theoretical aspects about batteries, energy storage and renewable energies and today's pupils and students are the generations which help shape the development of the energy transition - not only in Germany!

\section{Acknowledgements}

The authors thank the $B M B F$ (Germany) and the Fonds der Chemischen Industrie (Germany) for the financial support.

\section{Statement of Competing Interests}

The authors have no competing interests.

\section{References}

[1] Bundesrat, "Gesetzesbeschluss des Deutschen Bundestages: Gesetz zur Einführung von Ausschreibungen für Strom aus erneuerbaren Energien und zu weiteren Änderungen des Rechts der erneuerbaren Energien," 08.07.16, https://dipbt.bundestag.de/dip21/brd/2016/0355-16.pdf.
[2] National Research Council Of The National Academies, "The National Academies Summit on America's Energy Future: Summary of a Meeting," CNRC-NRC, www.nap.edu/download/12450.

[3] A. Z. Weber, M. M. Mench, J. P. Meyers et al., "Redox flow batteries: A review," Journal of Applied Electrochemistry, vol. 41, no. 10, pp. 1137-1164, 2011.

[4] J. Noack, N. Roznyatovskaya, T. Herr et al., "Die Chemie der Redox-Flow-Batterien," Angewandte Chemie, vol. 127, no. 34, pp. 9912-9947, 2015.

[5] C. Ponce de León, A. Frías-Ferrer, J. González-García et al., "Redox flow cells for energy conversion," Journal of Power Sources, vol. 160, no. 1, pp. 716-732, 2006.

[6] P. Bottke and M. Winter, "Primäre und wiederaufladbare LithiumIonen-Batterien,” TU Graz - Institut für Chemische Technologie von Materialien, 2013,

https://www.tugraz.at/fileadmin/user_upload/Institute/ICTM/educ ation/downloads/Skript_Lithium-Ionen-Batterien.pdf.

[7] A. F. Holleman, E. Wiberg, and N. Wiberg, Lehrbuch der anorganischen Chemie, de Gruyter, Berlin, 2007.

[8] A. Parasuraman, T. M. Lim, C. Menictas et al., "Review of material research and development for vanadium redox flow battery applications," Electrochimica Acta, vol. 101, pp. 27-40, 2013.

[9] S. Liu, L. Wang, B. Zhang et al., "Novel sulfonated polyimide/polyvinyl alcohol blend membranes for vanadium redox flow battery applications," Journal of Materials Chemistry A, vol. 3, no. 5, pp. 2072-2081, 2015.

[10] J. Winsberg, T. Hagemann, T. Janoschka et al., "Redox-Flow Batteries: From Metals to Organic Redox-Active Materials," Angewandte Chemie (International ed. in English), vol. 56, no. 3, pp. 686-711, 2017.

[11] S. Roe, C. Menictas, and M. Skyllas-Kazacos, "A High Energy Density Vanadium Redox Flow Battery with $3 \mathrm{M}$ Vanadium Electrolyte," Journal of The Electrochemical Society, vol. 163, no. 1, A5023-A5028, 2016.

[12] T. Nguyen and R. F. Savinell, "Flow Batteries," The Electrochemical Society Interface, vol. 19, no. 3, pp. 54-56, 2010.

[13] P. K. Leung, T. Martin, A. A. Shah et al., "Membrane-less hybrid flow battery based on low-cost elements," Journal of Power Sources, vol. 341, pp. 36-45, 2017.

[14] D. Chen, M. A. Hickner, E. Agar et al., "Selective anion exchange membranes for high coulombic efficiency vanadium redox flow batteries," Electrochemistry Communications, vol. 26, pp. 37-40, 2013.

[15] D. Rosenberg, S. Pansegrau, M. Wachholz et al., "Redox-FlowBatterien - Organische Batterien mit Zukunftsperspektiven," CHEMKON, vol. 24, no. 4, pp. 325-330, 2017.

[16] S. Selverston, R. F. Savinell, and J. S. Wainright, "Zinc-Iron Flow Batteries with Common Electrolyte," Journal of The Electrochemical Society, vol. 164, no. 6, A1069-A1075, 2017.

[17] J. Novotny, D. Quarthal, and M. Oetken, "Farbspiel in Redoxflussbatterien," Nachrichten aus der Chemie, vol. 65, no. 6, pp. 672-675, 2017.

[18] D. Quarthal, J. Novotny, and M. Oetken, "Die „Blue Bottle“Redox-Flow-Batterie," CHEMKON, vol. 25, no. 2, pp. 74-81, 2018.

[19] J. Novotny, D. Quarthal, A. Solovev et al., "'Colourful energy' from the Caribbean - a hybrid redox flow battery with Blue Curaçao," CHEMKON, 2018.

(C) The Author(s) 2019. This article is an open access article distributed under the terms and conditions of the Creative Commons Attribution (CC BY) license (http://creativecommons.org/licenses/by/4.0/). 